\title{
Targeting mitochondrial metal dyshomeostasis for the treatment of neurodegeneration
}

Jeffrey R. Liddell ${ }^{1}$

${ }^{1}$ Department of Pathology, University of Melbourne, Victoria, Australia.

\author{
Address correspondence to: \\ Jeffrey R. Liddell \\ Department of Pathology \\ University of Melbourne \\ Ph: +6139035 6041 \\ Email: jliddell@unimelb.edu.au
}

\section{KEYWORDS}

Mitochondria; Alzheimer's disease; Parkinson's disease; Huntington's disease; amyotrophic lateral sclerosis; Friedreich's ataxia; superoxide dismutase; chelating agents; $\mathrm{Cu}$-atsm; deferiprone.

\footnotetext{
ABBREVIATIONS

6OHDA, 6-hydroxydopamine; $A \beta$, amyloid- $\beta$; AD, Alzheimer's disease; ALS, amyotrophic lateral sclerosis; APP, amyloid precursor protein; BBB, blood-brain barrier; CNS, central nervous system; $\mathrm{Cu}^{\mathrm{II}}$ (atsm), diacetylbis(4methylthiosemicarbazonato) $\mathrm{Cu}^{\mathrm{II}} ; \mathrm{Cu}^{\mathrm{II}}$ (gtsm), glyoxalbis(N(4)methylthiosemicarbazonato)Cu${ }^{\text {II }}$; DFO, deferoxamine; DMT1, divalent metal transporter 1; FRDA, Friedreich's ataxia; HD, Huntington's disease; Htt, huntingtin; IMS, intermembrane space; IRP1, iron responsive element binding protein 1; M30, 5-((methyl(2-propynyl)amino)methyl)-8-quinolinol; MCF, mitochondrial carrier family; MPTP, 1-methyl-4-phenyl-1,2,3,6-tetrahydropyridine; MRI, magnetic resonance imaging; NBIA, neurodegeneration with brain iron accumulation; PD, Parkinson's disease; PINK1, PTEN-induced putative kinase 1; ROS, reactive oxygen species; SOD1, superoxide dismutase 1; SOD2, superoxide dismutase 2; TDP-43, TAR DNA binding protein 43; TfR2, transferrin receptor 2; VCP, valosin-containing protein; VK28, 5-((4-(2-Hydroxyethyl)-1piperazinyl)methyl)-8-quinolinol.
} 


\begin{abstract}
Mitochondrial impairment and metal dyshomeostasis are suggested to be associated with many neurodegenerative disorders including Alzheimer's disease, Parkinson's disease, Huntington's disease, amyotrophic lateral sclerosis and Friedreich's ataxia. Treatments aimed at restoring metal homeostasis are highly effective in models of these diseases, and clinical trials hold promise. However in general the effect of these treatments on mitochondrial metal homeostasis is unclear, and the contribution of mitochondrial metal dyshomeostasis to disease pathogenesis requires further investigation. This review describes the role of metals in mitochondria in health, how mitochondrial metals are disrupted in neurodegenerative diseases, and potential therapeutics aimed at restoring mitochondrial metal homeostasis and function.
\end{abstract}

\title{
EXECUTIVE SUMMARY
}

Metals in mitochondria: Mitochondria play an important role modulating cellular metal levels, including heme and Fe-S cluster synthesis. However much is still to be elucidated regarding the mechanisms of metal trafficking.

Neurodegenerative diseases: Alzheimer's disease, Parkinson's disease, Huntington's disease, amyotrophic lateral sclerosis and Friedreich's ataxia all show changes in mitochondrial function and potentially altered metal homeostasis.

Friedreich's ataxia: Defect in protein involved in Fe-S cluster assembly causes mitochondrial iron accumulation and cytosolic iron depletion. Iron chelators that redistribute iron are showing potential for the treatment of this condition.

Amyotrophic lateral sclerosis: Cellular potential for metallation of SOD1 contributes to its propensity to aggregate, which correlates with disease progression and severity, and may be driven by SOD1 localised to mitochondria. Treatments delivering copper alleviate symptoms in animal models.

Alzheimer's disease: Presence of metals in extracellular amyloid plaques, decreased cellular copper and zinc, and increased cellular iron. Redistribution of metals by ionophores is highly effective in animal models and clinical trials have generated encouraging results.

Huntington's disease: Although relatively underexamined, evidence exists for altered metal distribution. The metal ionophore PBT2 showed improvement in cognitive function but no change in motor impairment in a recent clinical trial.

Parkinson's disease: Mitochondrial impairment concurrent with iron accumulation and copper deficiency, which can be recapitulated by disease-associated mitochondrial toxins. Both copper delivery and iron redistribution restore function in animal models. Conclusions: Treatments aimed at redistributing metals have demonstrated effectiveness in these neurodegenerative diseases. However, further studies are required to determine the extent to which these effects relate to mitochondrial metal homeostasis, which will determine the degree to which mitochondrial metal dyshomeostasis drives disease, and whether it is a valid therapeutic target.

\section{METALS IN THE BRAIN}

The central nervous system (CNS) is physically isolated from the rest of the body by the blood-brain and blood-cerebrospinal fluid barriers. Entry and exit of molecules including metals are highly regulated. With the exception of during development before the barriers are fully formed, the majority of iron trafficks these barriers via transferrin, 
[1]. Copper likely enters the brain as free copper via the copper importer copper transporter 1 and exporter ATP7A [2]. Zinc is transported via 24 proteins divided into ZIPs that increase cytosolic zinc and ZnTs which decrease cytosolic zinc [3].

In addition to their roles in mitochondria (see below) and protein folding and DNA regulation [3], transition metals such as iron, copper and zinc have specific roles in the brain. Copper and iron are required for synthesis of several neurotransmitters including dopamine, noradrenaline, adrenaline and 5-hydroxytrytamine [4,5]. Zinc and to a lesser extent copper are involved in neurotransmission, being released from vesicles into the synaptic cleft at up to high micromolar concentrations [3,5]. Iron is also critical for myelination of axons [4], while copper is required for iron trafficking via ceruloplasmin [5].

Mitochondrial impairment and metal dyshomeostasis are suggested to be associated with many neurodegenerative disorders. For some, such as Menkes disease, Wilson's disease, and neurodegeneration with brain iron accumulation (NBIA), their pathogenesis is clearly linked to metal dyshomeostasis. However, this review will focus on other more common disorders including Alzheimer's disease, Parkinson's disease, Huntington's disease, amyotrophic lateral sclerosis and Friedreich's ataxia, for which a causative link is uncertain.

\section{METALS IN MITOCHONDRIA}

Mitochondria are small organelles responsible for generating energy via the electron transport chain, as well as roles in cell cycle and metal regulation. They are particularly important for the CNS given its high dependency on mitochondrial energy production: 95\% of total energy for the CNS is estimated to be derived from mitochondria, predominantly for ion transport to maintain membrane gradients [6]. Almost half of all proteins require a metal ion to function [7], and the mitochondrial proteome consists of about 1000 proteins, of which mitochondrial DNA encodes for only 13 [8]. Mitochondria have a key role in regulating cellular metal levels, hence mitochondrial metal homeostasis may contribute to the pathogenesis of neurodegenerative diseases and may be a key target for therapeutic interventions. Many important mitochondrial enzymes require transition metals such as iron, copper, zinc and manganese. The electron transport chain complexes contain multiple Fe-S clusters, heme moieties and copper centers (Fig. 1). Mitochondria are also the predominant site for the biosynthesis of Fe-S clusters [9] and initiation of heme synthesis [10]. Mitochondria are also responsible for generating substantial amounts of reactive oxygen species (ROS) in the form of superoxide and in turn hydrogen peroxide as a byproduct of the electron transport chain [11]. Metals including iron and copper can catalyse the generation highly reactive hydroxyl radicals from superoxide and peroxides, and dysregulation of mitochondrial metals in neurodegeneration can impact mitochondrial function, cause excessive generation of ROS and oxidative damage. Therefore these metals must be tightly regulated in mitochondria to prevent such reactions. Despite a great deal known about these processes, much is still to be elucidated regarding the trafficking and regulation of metals in mitochondria.

\section{Mitochondrial metal trafficking}

The outer mitochondrial membrane has $2-3 \mathrm{~nm}$ pores, allowing the traverse of small molecules including metals [12]. In addition, the iron transporter, divalent metal 
transporter 1 (DMT1), has been detected in mitochondria [13], and may contribute to iron uptake across the outer mitochondrial membrane. Localisation of DMT1 to mitochondria in the brain is yet to be established.

In contrast to the outer mitochondrial membrane, the inner mitochondrial membrane is impermeable to solutes and metal ions. Transport into the mitochondrial matrix is achieved predominantly (but not exclusively) via transporters of the mitochondrial carrier family (MCF) of which humans have 53 and yeast have 35 [14]. In mammals, mitoferrin 1 and mitoferrin 2 transport iron across the inner mitochondrial membrane $[15,16]$. Mammalian copper, manganese and zinc transporters are yet to be identified.

In contrast, transporters for iron, copper, manganese and zinc have been identified in yeast. Yeast transport iron into the mitochondrial matrix via the mitoferrin homologues Mrs3 and Mrs4 [17], and potentially to a lesser extent by Mmt1, Mmt2 [18] and Rim2 [19]. In addition to iron import, yeast proteins Mrs3, Mrs4 and Rim2 can also import copper ions $[19,20]$, and recently another MCF protein, Pic2, was also found to import copper into the mitochondrial matrix in yeast [21]. Manganese is imported via Smf $2 p$ and Mtm1p [22]. How zinc ions are imported into the mitochondrial matrix is currently unclear, although Rim2 in yeast is capable of importing zinc [19]. These yeast studies suggest mammalian metal ion transport likely involves additional MCF transporters.

No mechanisms for the export of iron ions from mitochondria have been definitively identified, raising the possibility that iron can only be exported from mitochondria as heme or Fe-S clusters, and any impairment of these processes will result in mitochondrial iron accumulation, as is the case in Friedreich's ataxia (see below).

An additional important pathway for metal redistribution and turnover from mitochondria is mitophagy, the lysosomal degradation of mitochondria, upon which metals contained with the degraded mitochondria can be redistributed from lysosomes throughout the cell. In depth analysis of the interactions between mitophagy, metal homeostasis and neurodegeneration is beyond the scope of the current review, however evidence for aberrant mitophagy in neurodegeneration is accumulating, including identification of the roles of Parkinson's disease-associated proteins parkin and PTENinduced putative kinase 1 (PINK1) in the regulation of mitophagy [23]. Furthermore, an interaction between the regulation of mitophagy and metal homeostasis is emerging [24-26].

\section{Mitochondrial metalloproteins}

The complexes of the electron transport chain are heavily dependent on iron, containing multiple Fe-S clusters and heme groups (Fig. 1). In addition, mitochondria contain many other iron-proteins, including a mitochondrial form of ferritin [27]. First discovered in 2001 [28], overexpression of mitochondrial ferritin causes mitochondrial iron accumulation and depletion of cytosolic iron [29]. Other mitochondrial ironproteins include the $\mathrm{Fe}-\mathrm{S}$ cluster-containing proteins ferrochelatase responsible for inserting iron into protoporphyrin IX to generate heme [30], ferredoxin involved in Fe$\mathrm{S}$ cluster biosynthesis [31,32], and the tricarboxylic acid cycle enzyme aconitase involved in converting citrate to isocitrate [33]. Unlike cytosolic aconitase, mitochondrial aconitase does not exhibit iron regulatory activity when deficient of its Fe-S cluster [33]. 
Free copper is highly reactive and is therefore very tightly regulated. Estimates of free copper in yeast is less than one atom per cell [34], and entering copper is immediately bound by high affinity chaperones such as ATOX1, COX17 and CCS, which chaperone copper to ATP7A, cytochrome c oxidase (complex IV), and superoxide dismutase 1 (SOD1), respectively [35,36]. Mitochondrial copper proteins include complex IV, SOD1, and their copper chaperones (Fig. 1).

Delivery and incorporation of copper into complex IV in mitochondria is a highly regulated process involving multiple chaperone and assembly proteins including COX17, COX11, SCO1 and SCO2 [37]. Disruption of SCO1 and SCO2 not only impairs complex IV activity but also causes cellular copper deficiency, in a process that seems to be dependent upon the complex IV assembly protein Cox19 [38]. This study therefore suggests that in addition to providing copper to complex IV, mitochondrial copper chaperones also regulate cellular copper levels.

SOD1 is an abundant antioxidant enzyme responsible for rapidly dismutating superoxide to hydrogen peroxide. A homodimer, each monomer contains a copper and zinc ion. Most SOD1 is cytoplasmic, but a small portion is located in the mitochondrial intermembrane space (IMS). Both SOD1 and its copper chaperone CCS enter mitochondria demetallated. CCS gains its copper ion within mitochondria, whereupon it metallates SOD1, preventing the exit of SOD1 from the mitochondrial IMS. Thus the location of SOD1 metallation depends on the location of CCS metallation [39]. Interestingly, the subcellular localization of CCS is modulated by oxygen concentration: high oxygen inhibits CCS import into mitochondria [39]. These high oxygen conditions are almost ubiquitous in in vitro systems, thus most in vitro conditions will suppress mitochondrial CCS, and therefore SOD1, localization.

Originally discovered in yeast, the mitochondrial matrix contains a dynamic pool of copper bound not to protein but to as-yet unidentified low molecular weight ligand/s [40]. This matrix-residing copper was subsequently detected in mouse mitochondria and appears to be the source for IMS COX17 and CCS [41]. The low molecular weight ligand could easily cross the outer mitochondrial membrane, and is hypothesised to cross the inner mitochondrial membrane via an as yet unknown transport mechanism.

In addition to SOD1, an important mitochondrial protein is superoxide dismutase 2 (SOD2). SOD2 is a homotetramer containing one manganese ion per monomer. Residing in the mitochondrial matrix, SOD2 is important for detoxifying superoxide generated from the electron transport chain [42].

While much remains to be elucidated regarding zinc in mitochondria, it appears that neuronal mitochondria have a labile pool of zinc that responds to cellular conditions [43]. Recent advances in fluorescence resonance energy transfer-based zinc sensors may further illuminate zinc regulation and trafficking between mitochondria and other organelles. For example, mitochondrial zinc is mobilised to the cytosol following glutamate exposure in neurons, while glutamate in the presence of zinc causes accumulation of zinc into neuronal mitochondria [44]. Mitochondrial zinc appears to change less rapidly than nuclear zinc [45], and mitochondrial zinc levels seem to vary between cell types [46]. 
Zinc is required in the mitochondrial matrix for zinc finger proteins [47], many of which are involved in protein transport across mitochondrial inner membrane [48]. Taking advantage of the propensity of zinc finger proteins to bind DNA, engineered zinc finger nucleases targeting mitochondrial DNA have been generated [49], and have been demonstrated to eliminate specifically-targeted mutated DNA [50]. This also suggests zinc and zinc finger proteins are involved in regulating transcription of mitochondrial DNA.

\section{FRIEDREICH'S ATAXIA}

Friedreich's ataxia (FRDA) is an inherited autosomal recessive neurodegenerative disease caused by GAA repeat expansion in the frataxin gene. Most commonly developing during childhood and adolescence [51], clinical features of FRDA include gait and limb ataxia resulting in poor balance and coordination [52]. Neuropathological indications include degeneration of the dentate nucleus in the cerebellum and the dorsal root ganglion, sensory and motor tracts of the spinal cord [53]. The mutation in the frataxin gene leads to deficiency of the mitochondrial matrix protein frataxin. FRDA patients exhibit abnormally low levels of frataxin, and the rate of degeneration correlates with the level of frataxin [54]. Frataxin is required for development: deletion of the frataxin gene is embryonically lethal in mice [55].

Frataxin is involved in Fe-S cluster biosynthesis in mitochondria [56]. Loss of frataxin impairs Fe-S cluster proteins, including mitochondrial respiratory chain complexes and aconitase [57-60]. Frataxin is also required for non-mitochondrial $\mathrm{Fe}-\mathrm{S}$ cluster proteins [61], hence although Fe-S cluster biosynthesis machinery is present in the cytosol of mammalian cells in addition to mitochondria [62], functional mitochondrial Fe-S cluster machinery is required for cytosolic Fe-S cluster generation [63]. Deficient Fe-S cluster biosynthesis caused by loss of frataxin directly impairs cellular iron regulation via the iron sensor, iron responsive element binding protein 1 (IRP1). IRP1 is a bifunctional cytosolic protein that displays aconitase activity when containing an Fe-S cluster. However, when Fe-S clusters are deficient, as in FRDA, IRP1 binds to iron responsive elements on the mRNA of iron regulatory proteins, regulating their expression to promote mitochondrial iron uptake in order to synthesis more $\mathrm{Fe}-\mathrm{S}$ clusters. Loss of frataxin also increases the mitochondrial iron importer mitoferrin 2 [64]. Hence disrupted frataxin results in mitochondrial iron overload and cytosolic iron depletion [65,66] (Fig. 2). This accumulation of mitochondrial iron causes mitochondrial impairment, possibly via iron-mediated radical generation $[65,66]$. Loss of frataxin also impairs heme biosynthesis as the final enzyme of heme synthesis, ferrochelatase, requires an Fe-S cluster. Reintroduction of frataxin to frataxin-deficient yeast cells corrects the iron imbalance between mitochondria and cytosol [67].

The above studies provide evidence for the role of frataxin in mitochondrial iron homeostasis. However, evidence for disrupted iron metabolism in FRDA patients is mixed. Several studies have detected signals consistent with elevated iron in the dentate nucleus of FRDA patients using non-invasive MRI and transcranial sonography methods [68-72]. However, a more recent MRI study found no apparent change in the iron content of dentate nucleus [73]. Furthermore, histological studies fail to detect iron deposits, changes in total iron or ferritin in the dentate nucleus or dorsal root ganglion of FRDA patients [74-77]. This has led some to conclude that Fe-S cluster deficiency is an inconsistent effect and mitochondrial iron accumulation a late event in FRDA 
[78]. These conflicting results could be explained by the fact that FRDA patients retain some frataxin, and this small remaining amount of frataxin may be sufficient to prevent the overt iron dysregulation observed in FRDA models. Indeed, clinically FRDA does seem to involve mild metal dyshomeostasis, such as redistribution of metals including iron, copper and zinc and metal-trafficking proteins including metallothioneins in the affected regions of human FRDA brain [76,77]. Furthermore, cells cultured from FRDA patients and mouse models exhibit a modest increase in mitochondrial iron [7982], and dysregulated mitochondrial iron is evident in human FRDA cardiac tissue $[57,74]$.

\section{Treatments for Friedreich's ataxia}

Iron-mediated radical generation is implicated in mitochondrial dysfunction in FRDA. Sequestering the excess mitochondrial iron by overexpression of mitochondrial ferritin is protective in fibroblasts from FRDA patients [83]. However, the clinical utility of this strategy is limited as it does not address the depletion of cytosolic iron. Therefore, therapies aimed at redistributing cellular iron have been studied. Potent iron chelators such as deferoxamine (DFO) are not appropriate as they deplete total iron content and actually decrease frataxin levels [84]. A better strategy involves the use of compounds with only moderate affinity for iron. Clinically approved for treatment of iron overload, deferiprone is able to redistribute iron subcellularly and can promote iron export to adjacent cells or to extracellular transferrin [85]. In the context of Parkinson's disease (PD), deferiprone was recently shown to decrease labile iron from mitochondria in vivo [86]. Deferiprone has shown efficacy in in vitro and drosophila models of FRDA, decreasing mitochondrial iron and improving mitochondrial function $[87,88]$, and was identified from a screen of small molecules as a compound inducing an increase in frataxin levels [89].

Deferiprone has been assessed in clinical trials for the treatment of FRDA. In a study of only nine adolescent FRDA patients, $20-30 \mathrm{mg} / \mathrm{kg} /$ day deferiprone treatment was demonstrated to specifically decrease the iron content of the dentate nucleus, as approximated by an indirect MRI method [69]. Treatment with deferiprone also seemed to improve ataxia symptoms, although there was no placebo group with which to compare [69]. In another trial of only FRDA patients, deferiprone $(20 \mathrm{mg} / \mathrm{kg} / \mathrm{day})$ combined with idebenone was found to decrease iron content of the dentate nucleus, but had mixed effects on symptoms [68]. More recently, a placebo-controlled clinical trial of deferiprone treatment in FRDA patients generated mixed results [90]. The lowest dose tested $(20 \mathrm{mg} / \mathrm{kg} /$ day $)$ induced possibly beneficial results in patients with mild disease, whereas higher doses worsened symptoms [90]. These trials indicate that redistributing iron may be an effective treatment for FRDA, but precise dosage control is required for optimal results.

\section{AMYOTROPHIC LATERAL SCLEROSIS}

Amyotrophic lateral sclerosis (ALS) is a fatal adult-onset neurodegenerative disease in which motor neurons in spinal cord and brain degenerate, resulting in progressive loss of motor function and paralysis [91]. Deterioration is rapid, and the average lifespan after diagnosis is 3-5 years [92]. Following the discovery of mutations in SOD1 in 1993 [93], a growing number of genes have been associated with the 5-10\% of familial ALS cases [94], including TAR DNA binding protein 43 (TDP-43), fused in sarcoma (FUS) and valosin-containing protein (VCP), while the causes of sporadic ALS are yet to be 
determined. Although mutations in SOD1 only account for up to $20 \%$ of familial cases [95], and therefore only 2\% of ALS patients, most data to date has been generated utilising SOD1 models.

One consistent feature of sporadic ALS patients [96] and multiple ALS models [97,98] is the presence of abnormal mitochondria in the spinal cord. Furthermore, a missense mutation in the CHCHD10 gene encoding a mitochondrial protein apparently important for mitochondrial structure and function has recently been associated with ALS and frontotemporal dementia, and muscle fibers from these patients exhibit mitochondrial abnormalities [99]. In addition to the well-characterised mitochondrial abnormalities reported in multiple mouse models of ALS involving overexpression of mutated SOD1 [97], mitochondrial abnormalities have also been reported in mutated VCP [100,101], TDP-43 [102,103], and FUS [104] models. This appears to be a very early pathological feature of transgenic ALS model mice: abnormal mitochondria are evident in mice expressing mutant SOD1 before symptom onset [102,105,106]. One report observed mitochondrial morphology changes as early as one week of age in spinal cord of mutant SOD1 mice [107]. That these abnormalities precede other pathology has led to speculation that mitochondrial impairment may be an initiating element in ALS.

ALS is associated with elevated iron, with increased iron and iron-related proteins in the serum of ALS patients [108], and elevated iron in motor cortex of ALS patients as detected by MRI [109-111]. Evidence from SOD1 mice indicates this includes elevated mitochondrial iron [112]. Little evidence for alteration in metals has been reported in non-SOD1 models, although TDP-43-A315T mice have recently been shown to exhibit elevated manganese, copper and zinc in the spinal cord [113]. Although yet to be confirmed, these changes may contribute to mitochondrial dysfunction.

\section{Interactions between superoxide dismutase 1 and mitochondria}

Although SOD1 is a mainly cytosolic protein, a small portion is localised within mitochondria. Evidence suggests the interaction of SOD1 with mitochondria is altered in ALS, and as SOD1 is a $\mathrm{Cu} / \mathrm{Zn}$ protein, this may have implications for metal homeostasis in ALS.

Most ALS-associated mutated forms of SOD1 retain their antioxidant enzymatic function, hence mutations in SOD1 appear to impart a toxic gain of function to the protein. Mutated forms of SOD1 are more prone to misfolding and aggregation than wild-type SOD1. Indeed, all SOD1-dependent familial ALS cases and some sporadic ALS cases exhibit SOD1 aggregations and inclusions in spinal cord motor neurons [114].

One hypothesis is that aggregated SOD1 impairs mitochondrial function. Misfolded mutated SOD1 associates with the cytoplasmic face of mitochondria [115], where it impairs mitochondrial functions, including binding and inhibiting mitochondrial voltage-dependent anion channel 1 [116], inhibiting mitochondrial import proteins [117] and toxic interactions with Bcl2 [118].

Additionally, a small portion of total cellular SOD1 is found within mitochondria, localised to the IMS. The presence of SOD1 in mitochondria appears to be important for normal function: SOD1-deficient motor neurons in vitro and in vivo show mitochondrial deficits and axonal abnormalities, and re-introduction of SOD1 
exclusively to mitochondria rescued this phenotype [119]. However, in mice expressing ALS-associated mutated forms of SOD1, SOD1 is found localised to mitochondria concurrent with mitochondrial abnormalities and impaired activity [120,121]. More recently, selective targeting of mutated SOD1 to mitochondria caused progressive disease recapitulating many features of ALS, but no muscle denervation [122]. Furthermore, improving mitochondrial function (via enhanced $\mathrm{Ca}^{2+}$ buffering) in multiple SOD1-dependent models of ALS decreased aggregation of SOD1 and rescued motor neurons, but did not extend survival or alter muscle denervation [123]. Hence mitochondrial SOD1 appears to play a key role in the pathogenesis of ALS, but alone cannot completely recapitulate the disease phenotype.

Localisation of SOD1 to the mitochondrial IMS is mediated by its oxidation and metallation. Mature SOD1 cannot enter mitochondria, only immature reduced apoSOD1 monomer can cross the outer mitochondrial membrane. Retention of SOD1 in mitochondria requires IMS-localised CCS $[124,125]$ for its maturation in the same manner as cytosolic SOD1 and CCS [126] (Fig. 3). Mature SOD1 cannot exit mitochondria, and as such is trapped in the mitochondrial IMS. Interestingly, copperloading is not required for mitochondrial retention of SOD1 [125], indicating the potential for mitochondrial accumulation of copper-deficient SOD1, potentially promoting mitochondrial dysfunction.

Aggregation of SOD1 is initiated by unfolded immature demetallated SOD1 monomers [127]. Hence the more or longer SOD1 exists in this immature state, the more likely aggregation will occur. This is mediated by three main factors: metallation, the level of expression, and the presence of mutations that lower the stability of the monomer. Inhibition of SOD1 metallation promotes aggregation by prolonging the half-life of the inherently unstable immature SOD1, increasing the likelihood of misfolding. Hence sufficient supply of $\mathrm{Cu}$ to SOD1 via CCS is essential. In regards to mutated forms of the protein, each mutation alters the stability of SOD1 to a different extent, and the propensity of each to aggregate correlates with disease progression [128]. Expression level of SOD1 also correlates with disease progression. For example, disease progression is dependent upon the expression level of SOD1-G93A in transgenic mice, where mice containing $\sim 25$ copies of the transgene (high-copy) have substantially shorter disease course than mice with 8-10 transgene copies (low-copy) [129], and even slower disease course in mice with very low expression of SOD1-G93A (4 copies) [130]. Furthermore, mice overexpressing wild-type SOD1 also develop mitochondria impairments [131] and ALS-like symptoms [132], albeit at a slower rate than mice overexpressing mutant SOD1. When these mice are crossed with SOD1-G93Aexpressing mice, disease course is accelerated as compared to SOD1-G93A alone [131]. This indicates that the absolute expression level of SOD1 contributes to disease progression, in synergy with the aggregation potential of the forms of SOD1 expressed.

Overexpression of SOD1 necessitates an elevated requirement for intracellular $\mathrm{Cu}$. Although SOD1 is already a highly abundant protein, it can be overexpressed up to 20fold in commonly used SOD1 mouse models [133]. This elevated demand for Cu could deplete other cellular cuproproteins such as complex IV in mitochondria, causing the mitochondrial and energy impairments evident in the animals. CCS overexpression would have much the same effect, sequestering $\mathrm{Cu}$ for SOD1 while depleting other cuproproteins. Indeed, double transgenic CCSxG93A-SOD1 mice exhibit impaired complex IV activity [134], likely due to elevated demand for copper by the 
overexpressed SOD1 and CCS depleting cellular copper for other purposes including complex IV. These mice exhibit a severe phenotype of extremely rapid death within 36 days along with severe mitochondrial impairment and accumulation of mitochondrial aggregated SOD1 [135].

The zinc content of SOD1 also contributes to its toxicity. Expression of zinc-deficient SOD1 renders drosophila hypersensitive to mitochondrial toxins and is neurotoxic [136]. Mice expressing mutated SOD1 also exhibit elevated CNS iron, including increased mitochondrial iron load and upregulated mitochondrial iron trafficking $[112,137,138]$.

It is important to note that the localization of SOD1 to mitochondria is modulated by additional factors that are relevant to in vitro models. Entry of CCS into mitochondria is dependent upon oxygen levels, whereby high oxygen concentrations such as those present in most in vitro systems inhibit CCS import into mitochondria [39]. Thus CCS and thereby SOD1 localisation to mitochondria will be suppressed under most in vitro conditions. Furthermore most in vitro environments contain supraphysiological glucose concentrations, shifting energy production from mitochondrial oxidative phosphorylation towards glycolysis. Hence there is a greatly diminished reliance on mitochondrial function in vitro as compared to in vivo conditions. These factors hamper the study of SOD1 in relation to mitochondria, potentially leading to an underappreciation of the importance of mitochondrial SOD1.

\section{Treatments for amyotrophic lateral sclerosis}

Most preclinical studies have utilised mutated SOD1 mouse models, and although testing of therapeutic strategies in non-SOD1 models is desirable, SOD1 mouse models still most closely recapitulate the disease phenotype.

The copper delivery compound diacetylbis(4-methylthiosemicarbazonato) $\mathrm{Cu}^{\text {II }}$ $\left(\mathrm{Cu}^{\mathrm{II}}(\mathrm{atsm})\right)$ has shown strong efficacy in both the SOD1-G93A and SOD1-G37R mouse models of ALS [139-141]. In these models, $\mathrm{Cu}^{\mathrm{II}}(\mathrm{atsm})$ treatment delayed symptom onset and progression, improved survival and prevented motor neuron death [139-141]. Interestingly, mutant SOD1 levels [141] and activity [139] were increased following $\mathrm{Cu}^{\mathrm{II}}\left(\right.$ atsm) treatment. Further examination revealed that $\mathrm{Cu}^{\mathrm{II}}($ atsm) increased the metallation of SOD1 in the spinal cord of the mice, with incorporation of the delivered $\mathrm{Cu}$ into endogenous SOD1 [141]. In a currently ongoing study, $\mathrm{Cu}^{\mathrm{II}}(\mathrm{atsm})$ treatment of double transgenic CCSxSOD1-G93A overexpressing mice has thus far abolished symptoms and prevented the rapid death evident in this model [142]. Exactly how $\mathrm{Cu}^{\mathrm{II}}(\mathrm{atsm})$ rescues the phenotype in these mice is unclear. One possibility is that $\mathrm{Cu}^{\mathrm{II}}(\mathrm{atsm})$ promotes the metallation and maturation of SOD1 in the cytosol, preventing entry into mitochondria. Alternatively, $\mathrm{Cu}^{\mathrm{II}}(\mathrm{atsm})$ may deliver $\mathrm{Cu}$ to mitochondria whereby apo-SOD1 is metallated in the mitochondrial IMS. Both scenarios promote the maturation of SOD1 and limit the presence of apo-SOD1 in mitochondria, potentially inhibiting SOD1 aggregation (Fig. 3). Regardless, these studies show that limiting the presence of apo-SOD1 by promoting SOD1 maturation via copper delivery slows disease progression.

Iron chelation has been shown to extend survival and improve locomotor function in the SOD1-G37R mouse model [112]. Furthermore, 8-hydroxyquinoline-derived compounds 5-((4-(2-Hydroxyethyl)-1-piperazinyl)methyl)-8-quinolinol (VK28) and 5- 
((methyl(2-propynyl)amino)methyl)-8-quinolinol (M30; Fig. 4) are also protective in SOD1-G93A mice $[138,143]$. These results were ascribed to the iron chelating effect of the compounds, alleviating iron accumulation and iron-mediated oxidative stress. The structurally related compounds clioquinol and PBT2 (Fig. 4), which share the metal-binding domain with VK-28 and M30, have been shown to redistribute both copper and zinc (see AD below). In addition to iron, M30 can also bind copper [144], while zinc binding has not been reported. Therefore, the possibility remains that the neuroprotective effects of M30 may also involve copper or zinc redistribution. However copper and zinc were not investigated, nor were the effects of these compounds on mitochondria.

A small phase I/II clinical trial assessed combined zinc (90mg/day) and copper $(2 \mathrm{mg} /$ day) administration in 8 ALS patients. The study reported the treatment was well tolerated, but had no effect on ALS progression [145].

\section{ALZHEIMER'S DISEASE}

Alzheimer's disease (AD) is an age-associated progressive neurodegenerative disease neuropathologically characterised by neuronal death, cortical amyloid plaques rich in amyloid- $\beta$ (A $\beta$ ) peptide and neurofibrillary tangles containing hyperphosphorylated tau. A prominent feature of AD brain is mitochondrial impairment (reviewed in [146]). Human AD brain displays evidence of decreased mitochondrial number and mitochondrial damage [147,148], decreased complex IV activity [149-151] and deletions in mitochondrial DNA correlate with impaired complex IV activity in human AD brain [152]. Transgenic mice modeling AD exhibit impaired mitochondrial function and reactive oxygen species (ROS)-related mitochondrial damage $[147,153,154]$. Indeed mitochondrial dysfunction is an early feature in transgenic AD mice (reviewed in [155]), as evidenced for example by impaired $\mathrm{Ca}^{2+}$ uptake [156] and decreased complex IV activity [157] from 2 months of age. Furthermore, A $\beta$ has been shown to accumulate in mitochondria in humans and transgenic mice [157-159], potentially contributing to mitochondrial dysfunction.

$\mathrm{AD}$ is also characterised by altered biometal homeostasis, including iron, copper and zinc [160]. Iron is elevated in human AD brain [161-163], whereas copper levels are decreased [164], specifically in the soluble phase [165]. Furthermore copper and zinc accumulate within extracellular amyloid plaques [166], potentially depleting intracellular copper and zinc levels. This could contribute to mitochondrial impairments such as the decreased complex IV activity evident in human AD brain [149-151].

Decreased cellular copper may also contribute to iron accumulation: insufficient cellular copper may impair activity of the cuproenzyme ceruloplasmin, important for iron export from glial cells, leading to cellular iron accumulation, as has been suggested for PD [167]. The amyloid precursor protein (APP) may also contribute to iron accumulation. While the exact function of APP is unknown, it seems to play a role in iron export from neurons with APP knockout cells and animals displaying neuronal iron accumulation $[168,169]$. Knockout of tau also leads to neuronal iron accumulation possibly via decreased trafficking of APP to the plasma membrane [170]. Accumulation of iron may influence mitochondria in $\mathrm{AD}$, as it has been shown that overexpression of mitochondrial ferritin prevents $A \beta$ toxicity in vitro, whereas knockdown increases $A \beta$ toxicity in vivo [171]. Furthermore, it may be through interactions with metals that 
mitochondrial impairment is driven or exacerbated by $\mathrm{A} \beta$ localised to mitochondria [159].

Treatments for Alzheimer's disease

Metal dyshomeostasis in AD includes localisation of copper and zinc in extracellular amyloid plaques, resulting in intracellular depletion of these metals, and iron accumulation within cells. Therapies aimed at redistributing metals have proven effective in models of AD. For example, the 8-hydroxyquinoline-derived metal ionophores clioquinol and PBT2 have been demonstrated to traffic copper and zinc into cells, prevent $A \beta$ toxicity in vitro, decrease extracellular $A \beta$ levels in vivo and improve the behavioural phenotype of AD model mice [172-175]. Clioquinol also effectively restored iron levels and reversed cognitive deficits in tau knockout mice, which develop symptoms consistent with both AD and PD [170,176]. Pyrrolidine dithiocarbamate, another copper ionophore, is similarly protective in the APP/PS1 mouse model of AD [177]. M30, a bifunctional iron-chelating compound containing the N-propargyl moiety of the monoamine oxidase inhibitor rasagiline and the same 8-hydroxyquinolinederived metal-binding domain as clioquinol and PBT2 (Fig. 4), also demonstrated cognitive and neuropathological benefits in APP/PS1 mice [178], while the potent iron chelator deferasirox conjugated to lactoferrin attenuated cognitive deficits in a rat $A \beta$ injection model of AD [179]. Delivery of exogenous copper to APP/PS1 mice via treatment with glyoxalbis(N(4)methylthiosemicarbazonato) $\mathrm{Cu}^{\mathrm{II}}\left(\mathrm{Cu}^{\mathrm{II}}(\mathrm{gtsm})\right)$ restored intracellular copper levels, decreased insoluble $\mathrm{A} \beta$ levels and improved cognition [180].

Metal redistribution therapies for the treatment of AD have also been assessed in clinical trials. Although designed to target aluminium and yet to be replicated, a placebo-controlled clinical trial in 1991 showed that the iron chelator DFO significantly slowed cognitive decline in AD patients [181]. Clioquinol and PBT2 have also been tested in phase II clinical trials of $\mathrm{AD}$, both exhibiting limited but promising results on cognitive function [182-184]. Although the utility of clioquinol is hampered by the potential for contamination during mass production, PBT2 has no such limitations.

Thus interventions aimed at correcting metal homeostasis improve neuronal function including mitochondrial function. However, the extent to which these treatments directly influence mitochondrial metals is unclear, and whether the restoration of mitochondrial function is a direct effect or subsequent to outcomes elsewhere in the cell is also unclear.

\section{HUNTINGTON'S DISEASE}

Huntington's disease (HD) is an inherited autosomal dominant neurodegenerative disease caused by a CAG expansion in the huntingtin gene. Characterised by progressive chorea and cognitive impairment, HD involves the selective loss of striatal neurons and aggregation of the mutated huntingtin $(\mathrm{Htt})$ protein. While the function of $\mathrm{Htt}$ is yet to be fully elucidated, mutant $\mathrm{Htt}$ is prone to proteolytic cleavage and neurotoxic aggregation [185]. HD features prominent mitochondrial dysfunction, possibly via interaction with mutant $\mathrm{Htt}$ [186].

While evidence for the involvement of metals in HD is limited, histological and MRI studies demonstrate elevated iron in the basal ganglia of HD patients (reviewed in 
[187]). Copper was also reported to be elevated in the basal ganglia of HD patients [188], although other studies report conflicting results, confirming elevated iron but not copper $[189,190]$. Nevertheless, iron and copper are elevated in transgenic Htt mice [191,192], and the quinolinic acid model of HD increases striatal copper content [193,194]. Furthermore, copper-related proteins are increased in HD brain, including ceruloplasmin and metallothionein $[189,195]$. Application of the iron chelator DFO induces $\mathrm{Htt}$ expression in vitro, suggesting a role for $\mathrm{Htt}$ in iron homeostasis [196]. The HD-associated mitochondrial toxin 3-nitropropionic acid causes zinc accumulation in vitro [197]. Whether these disruptions in metal homeostasis extend to mitochondria is yet to be confirmed.

\section{Treatments for Huntington's disease}

Although striatal copper content is increased in HD patients and the quinolinic acid model of HD, copper supplementation before quinolinic acid treatment boosted antioxidant defenses in mice [194]. Intraventricular treatment with the iron chelator DFO improved the motor phenotype of transgenic Htt mice [192]. Treatment with the metal ionophore PBT2 extended survival and improved motor function in transgenic Htt mice [198]. Very recently, a phase II clinical trial of PBT2 in HD patients found limited although promising results of the drug on cognitive function, but no effect on motor function [199]. As the mechanism of action of PBT2 is thought to involve redistribution of metals (see above), these results suggest that the metal dyshomeostasis evident in HD may be involved in pathogenesis of the disease. As with similar treatments for $\mathrm{AD}$, the effect of these treatments on mitochondrial metals and function remain unclear.

\section{PARKINSON'S DISEASE}

PD is a progressive age-related neurodegenerative disease characterised by motor (resting tremor, bradykinesia, and rigidity) and cognitive impairments [200]. Neuropathologically, PD involves a selective loss of dopaminergic neurons in the substantia nigra region of the basal ganglia and $\alpha$-synuclein aggregation in Lewy bodies [201,202].

Mitochondria are hypothesised to be a key target in PD. Mitochondrial complex I is deficient in the affected brain regions in human PD brain [203,204], and mitochondria of the substantia nigra are exquisitely sensitive to mitochondrial toxins such as rotenone, 6-hydroxydopamine (6OHDA), 1-methyl-4-phenyl-1,2,3,6tetrahydropyridine (MPTP) and paraquat. Exposure to these toxins recapitulates many pathological features of $\mathrm{PD}$, and exposure in humans has been linked to increased risk of acquiring PD [205].

The substantia nigra of PD brain also exhibits elevated iron (reviewed in [206]) and diminished copper content [207,208], which may contribute to mitochondrial deficits. Activities of copper trafficking proteins [208] and cuproproteins such as ceruloplasmin [167] are also impaired in PD, leading to decreased cellular copper and increased cellular iron, respectively. Not only is iron elevated in human PD brain, but also in response to PD-related mitochondrial toxins including MPTP in monkeys [209,210] and mice [211,212], rotenone in monkeys and rats [213], and 6OHDA in rats [214]. MPTP treatment of mice also decreases copper content [215], ceruloplasmin activity [167] and ferroportin levels [212] in the substantia nigra, all of which promote cellular 
iron accumulation. Tau deficiency also causes nigral iron accumulation and parkinsonism in transgenic mice [170].

The elevated nigral iron levels have been reported to be mainly localised to mitochondria [216]. That mitochondrial toxins implicated in PD cause iron accumulation strongly indicates a direct link between nigral iron content and mitochondrial activity. One hypothesis suggests that inhibition of complex I increases ROS levels, impairing Fe-S cluster assembly, leading to disrupted regulation of iron and mitochondrial iron accumulation reminiscent of FRDA (Fig. 2) [213]. Also contributing to impaired Fe-S cluster assembly and therefore mitochondrial iron accumulation is depletion of nigral glutathione, which is a consistent pathological hallmark of PD [217-219]. Glutathione is required for glutaredoxin 2 to facilitate Fe-S cluster assembly [220]. Hence glutathione, iron and mitochondrial dysfunction appear to be inextricably linked in the pathogenesis of PD. Which of these factors initiate disease and which are downstream remains unclear.

Zinc is also disrupted in PD. Deficiency of ATP13A2 protein (otherwise known as PARK9, in which mutations are associated with PD) was recently shown to induce mitochondrial zinc accumulation and dysfunction [221], and PD-associated toxins cause zinc accumulation in vitro [197].

\section{Treatment for Parkinson's disease}

As iron is elevated in the substantia nigra in PD, many treatments for PD have focused upon sequestering this iron. Genetic overexpression of mitochondrial ferritin protects against MPTP and 6OHDA toxicity in mice [222,223], and also depletes cytosolic iron, preventing 6OHDA-induced iron redistribution and mitochondrial damage [223].

Pharmacological iron chelation paradigms have shown efficacy in several in vivo models of PD. DFO administration is protective in animal models of PD [224-228]. However, in these studies DFO was injected directly into the brain or administered to weanling mice without fully functional blood-brain barrier (BBB). Peripherally administered DFO has shown efficacy in 6OHDA-treated rats, although the first dose was administered prior to 6OHDA application [229]. DFO is highly water-soluble and there is only limited evidence that it can cross the BBB. Compounds aimed at improving the BBB permeability of DFO have greatly potentiated neuroprotective effects in vitro [230], and may have improved efficacy in vivo.

The clinically available cell-permeant iron chelators deferiprone and deferasirox protect dopaminergic neurons in the substantia nigra of rats against 6OHDA toxicity when administered peripherally before 6OHDA and deferasirox also when administered directly to the substantia nigra after 6OHDA lesion [229]. Deferiprone also effectively rescues nigral dopaminergic neurons, decreases mitochondrial iron and rescues motor impairment in MPTP-treated mice [86].

Following the success of these studies in animal models, deferiprone was recently tested in a placebo-controlled clinical trial of PD patients [86]. This study demonstrated for the first time that clinical iron chelation is an effective therapeutic option for the treatment of PD. Deferiprone treatment improved symptoms in PD patients and specifically decreased nigral iron content. Importantly, this treatment did not affect systemic iron levels or those of other brain regions. As discussed above, rather than 
simply sequester iron, deferiprone has been shown to subcellularly redistribute iron [85]. Hence, redistribution of iron out of the mitochondria of nigral neurons may contribute to this clinically effective treatment in PD patients.

The copper content of the substantia nigra is specifically decreased in PD [207,208]. Administration of copper sulfate protects against MPTP toxicity [231]. Paradoxically, copper sequestration via the copper chelator D-penicillamine also provides partial protection against MPTP toxicity in mice, albeit at high doses [232]. Delivery of copper via $\mathrm{Cu}^{\mathrm{II}}(\mathrm{atsm})$ potently rescues dopaminergic neurons in the substantia nigra of PD model mice, including 6OHDA and MPTP models [233]. The mechanism of action of $\mathrm{Cu}^{\mathrm{II}}$ (atsm) is uncertain, but given that PD substantia nigra is deficient in copper and that $\mathrm{Cu}^{\mathrm{II}}(\mathrm{atsm})$ is effective in mitochondrial toxin models suggests the delivery of copper may improve mitochondrial function.

8-hydroxyquinoline-derived compounds have been investigated as therapeutics for PD. Clioquinol, VK28 and M30 all contain the same metal-binding domain (Fig. 4). Clioquinol treatment protects against MPTP toxicity in mice [222] and MPP toxicity in vitro [212]. VK28 prevents 6OHDA-induced loss of striatal dopamine in rats, and prevents mitochondrial lipid peroxidation in response to iron in vitro [234]. M30, a multifunctional molecule combining the metal-chelating 8-hydroquinoline domain with the monoamine oxidase inhibitor domain of the PD drug rasagiline [235], is neuroprotective when administered to mice following MPTP insult, preventing dopamine depletion, restoring tyrosine hydroxylase levels and preventing loss of dopaminergic neurons [236]. The effects of these 8-hydroxyquinoline-derived compounds have been largely ascribed to iron chelation or stabilization of hypoxia inducible factor- $1 \alpha$ via iron chelation-mediated prolyl hydroxylase inhibition [212,237]. However, the neuroprotective effects of these compounds may additionally be in part due to copper or zinc redistribution in the brain, as appears to be the case for the 8-hydroxquinoline-derived compounds clioquinol and PBT2 in the context of AD (see above). Indeed, M30 also reportedly binds copper [144], while zinc binding has not been reported. Trafficking of metals other than iron by VK28 or M30 remains to be investigated, and the effect of these interventions on mitochondrial metals has not been studied in detail.

\section{FUTURE PERSPECTIVES}

Neurodegenerative diseases including AD, PD, ALS, HD and FRDA all prominently feature mitochondrial dysfunction and metal dyshomeostasis. Treatments aimed at correcting metal homeostasis are highly effective in animal models of these diseases. However, further investigation in disease models is required to elucidate the mechanism of action of these treatments and to what extent they modulate mitochondrial metals and function. Redistribution of metals has thus far proven to be a valid therapeutic strategy, with recent clinical trials demonstrating beneficial effects. This success justifies more extensive clinical testing to clarify their potential clinical utility. It is important to consider the changes in mitochondrial metals in the context of disease pathology, involving neuronal death and extensive gliosis. For example, iron released from dying neurons may be accumulated in adjacent glia, and a loss of copper may reflect the loss of mitochondrial complex IV from dying neurons. This highlights the need for further investigation at the cellular level to elucidate the causes of metal changes. Together these studies will determine the contribution of mitochondrial metal 
dyshomeostasis to disease pathogenesis, and whether direct targeting of mitochondrial function and metal trafficking is a valid therapeutic target.

\section{ACKNOWLEDGEMENTS}

JRL is supported by a National Health and Medical Research Council Peter Doherty Fellowship.

\section{FIGURE LEGENDS}

Figure 1. Mitochondrial metalloproteins. Some of the most important metalloproteins in mitochondria are depicted. Iron-containing proteins include complexes of the electron transport chains, aconitase, ferredoxin and ferrochelatase, the latter two involved in Fe-S cluster (red squares) assembly and heme synthesis (red octagon), respectively. Mitochondrial ferritin resides in the matrix and stores iron in much the same manner as cytosolic ferritin. SOD1 in the intermembrane space contains 2 copper and zinc ions, while the manganese protein SOD2 resides in the matrix. The matrix also contains labile iron (red circles), copper (green circles) and zinc (blue circles).

Figure 2. Iron dyshomeostasis in Friedreich's ataxia. Under normal conditions, frataxin is involved in Fe-S cluster (red square) assembly in mitochondria. Fe-S cluster association with IRP1 prevents its iron regulatory actions. In Friedreich's ataxia, frataxin is depleted, leading to a deficiency of Fe-S assembly. IRP1 lacking Fe-S upregulates translation of iron trafficking proteins, leading to elevated iron (red circles) uptake. As there is a need for Fe-S clusters, iron is trafficked to mitochondria, resulting in mitochondrial iron overload and cytosolic iron depletion.

Figure 3. Superoxide dismutase 1 (SOD1) in mitochondria. In the cytosol, the mature, copper- (green circles) and zinc- (blue circles) containing SOD1 homodimer (dark grey) is formed when apo-SOD1 monomer receives copper from its chaperone CCS (light grey; 1). Apo-SOD1 monomer can also enter the mitochondrial intermembrane space, where it matures by association with CCS also localised to the mitochondrial intermembrane space (2), and is then trapped and cannot exit mitochondria. Apo-SOD1 can also aggregate within mitochondria (3), potentially causing mitochondrial dysfunction. The copper delivery drug $\mathrm{Cu}^{\mathrm{II}}(\mathrm{atsm})$ can deliver copper to the cytosol or mitochondria, providing copper for CCS (4), promoting the maturation of SOD1 and preventing SOD1 aggregation.

Figure 4. Structure of 8-hydroxyquinoline-derived compounds. These compounds have been assessed in animal models and clinical trials for the treatment of neurodegenerative diseases, variously alleviating symptoms and extending survival. The compounds all retain the quinoline ring nitrogen atom and phenolate oxygen atom metal-binding domain of 8-hydroxyquinoline.

\section{REFERENCES}

1. Moos T, Rosengren Nielsen T, Skjorringe T, Morgan EH. Iron trafficking inside the brain. J. Neurochem., 103(5), 1730-1740 (2007).

2. Choi BS, Zheng W. Copper transport to the brain by the blood-brain barrier and blood-CSF barrier. Brain Res., 1248, 14-21 (2009). 
3. Marger L, Schubert CR, Bertrand D. Zinc: an underappreciated modulatory factor of brain function. Biochem. Pharmacol., 91(4), 426-435 (2014).

4. Hare D, Ayton S, Bush A, Lei P. A delicate balance: Iron metabolism and diseases of the brain. Front. Aging Neurosci., 5, 34 (2013).

5. Scheiber IF, Mercer JF, Dringen R. Metabolism and functions of copper in brain. Prog. Neurobiol., 116, 33-57 (2014).

6. Vergun O, Dineley KE, Reynold IJ. Ion transport and energy metabolism. In: Handbook of Neurochemistry and Molecular Neurobiology. Lajtha, A (Ed. (Springer Science+Business Media, New York, USA, 2007) 429-463.

7. Waldron KJ, Rutherford JC, Ford D, Robinson NJ. Metalloproteins and metal sensing. Nature, 460(7257), 823-830 (2009).

8. Calvo SE, Mootha VK. The mitochondrial proteome and human disease. Annu. Rev. Genomics Hum. Genet., 11, 25-44 (2010).

9. Stehling O, Wilbrecht C, Lill R. Mitochondrial iron-sulfur protein biogenesis and human disease. Biochimie, 100, 61-77 (2014).

10. Nilsson R, Schultz IJ, Pierce EL et al. Discovery of genes essential for heme biosynthesis through large-scale gene expression analysis. Cell Metab., 10(2), 119-130 (2009).

11. Drose S, Brandt U, Wittig I. Mitochondrial respiratory chain complexes as sources and targets of thiol-based redox-regulation. Biochim. Biophys. Acta, 1844(8), 1344-1354 (2014).

12. $\mathrm{Xu} \mathrm{W}$, Barrientos $\mathrm{T}$, Andrews NC. Iron and copper in mitochondrial diseases. Cell Metab., 17(3), 319-328 (2013).

13. Wolff NA, Ghio AJ, Garrick LM et al. Evidence for mitochondrial localization of divalent metal transporter 1 (DMT1). FASEB J., (2014).

14. Palmieri F. Mitochondrial transporters of the SLC25 family and associated diseases: a review. J. Inherit. Metab. Dis., 37(4), 565-575 (2014).

15. Paradkar PN, Zumbrennen KB, Paw BH, Ward DM, Kaplan J. Regulation of mitochondrial iron import through differential turnover of mitoferrin 1 and mitoferrin 2. Mol. Cell Biol., 29(4), 1007-1016 (2009).

16. Shaw GC, Cope JJ, Li L et al. Mitoferrin is essential for erythroid iron assimilation. Nature, 440(7080), 96-100 (2006).

17. Foury F, Roganti T. Deletion of the mitochondrial carrier genes MRS3 and MRS4 suppresses mitochondrial iron accumulation in a yeast frataxin-deficient strain. J. Biol. Chem., 277(27), 24475-24483 (2002).

18. Li L, Kaplan J. Characterization of two homologous yeast genes that encode mitochondrial iron transporters. J. Biol. Chem., 272(45), 28485-28493 (1997).

19. Froschauer EM, Rietzschel N, Hassler MR et al. The mitochondrial carrier Rim2 co-imports pyrimidine nucleotides and iron. Biochem. J., 455(1), 57-65 (2013).

20. Froschauer EM, Schweyen RJ, Wiesenberger G. The yeast mitochondrial carrier proteins Mrs3p/Mrs4p mediate iron transport across the inner mitochondrial membrane. Biochim. Biophys. Acta, 1788(5), 1044-1050 (2009).

21. Vest KE, Leary SC, Winge DR, Cobine PA. Copper import into the mitochondrial matrix in Saccharomyces cerevisiae is mediated by Pic2, a mitochondrial carrier family protein. J. Biol. Chem., 288(33), 23884-23892 (2013).

22. Culotta VC, Yang M, O'Halloran TV. Activation of superoxide dismutases: putting the metal to the pedal. Biochim. Biophys. Acta, 1763(7), 747-758 (2006). 
23. Wong YC, Holzbaur EL. Autophagosome dynamics in neurodegeneration at a glance. J. Cell Sci., 128(7), 1259-1267 (2015).

24. Chatterjee S, Sarkar S, Bhattacharya S. Toxic metals and autophagy. Chem. Res. Toxicol., 27(11), 1887-1900 (2014).

25. Krishan S, Jansson PJ, Gutierrez E, Lane DJ, Richardson D, Sahni S. IRON METABOLISM AND AUTOPHAGY: A POORLY EXPLORED RELATIONSHIP THAT HAS IMPORTANT CONSEQUENCES FOR HEALTH AND DISEASE. Nagoya J. Med. Sci., 77(1-2), 1-6 (2015).

26. Lopes da Fonseca T, Outeiro TF. ATP13A2 and Alpha-synuclein: a Metal Taste in Autophagy. Exp. Neurobiol., 23(4), 314-323 (2014).

27. Finazzi D, Arosio P. Biology of ferritin in mammals: an update on iron storage, oxidative damage and neurodegeneration. Arch. Toxicol., 88(10), 1787-1802 (2014).

28. Levi S, Corsi B, Bosisio M et al. A human mitochondrial ferritin encoded by an intronless gene. J. Biol. Chem., 276(27), 24437-24440 (2001).

29. Nie G, Sheftel AD, Kim SF, Ponka P. Overexpression of mitochondrial ferritin causes cytosolic iron depletion and changes cellular iron homeostasis. Blood, 105(5), 2161-2167 (2005).

30. Ajioka RS, Phillips JD, Kushner JP. Biosynthesis of heme in mammals. Biochim. Biophys. Acta, 1763(7), 723-736 (2006).

31. Sheftel AD, Stehling O, Pierik AJ et al. Humans possess two mitochondrial ferredoxins, Fdx1 and Fdx2, with distinct roles in steroidogenesis, heme, and Fe/S cluster biosynthesis. Proc. Natl. Acad. Sci. U. S. A., 107(26), 11775-11780 (2010).

32. Shi Y, Ghosh M, Kovtunovych G, Crooks DR, Rouault TA. Both human ferredoxins 1 and 2 and ferredoxin reductase are important for iron-sulfur cluster biogenesis. Biochim. Biophys. Acta, 1823(2), 484-492 (2012).

33. Tong WH, Rouault TA. Metabolic regulation of citrate and iron by aconitases: role of iron-sulfur cluster biogenesis. Biometals, 20(3-4), 549-564 (2007).

34. Rae TD, Schmidt PJ, Pufahl RA, Culotta VC, O'Halloran TV. Undetectable intracellular free copper: the requirement of a copper chaperone for superoxide dismutase. Science, 284(5415), 805-808 (1999).

35. Nevitt T, Ohrvik H, Thiele DJ. Charting the travels of copper in eukaryotes from yeast to mammals. Biochim. Biophys. Acta, 1823(9), 1580-1593 (2012).

36. Robinson NJ, Winge DR. Copper metallochaperones. Annu. Rev. Biochem., 79, 537-562 (2010).

37. Horn D, Barrientos A. Mitochondrial copper metabolism and delivery to cytochrome c oxidase. IUBMB Life, 60(7), 421-429 (2008).

38. Leary SC, Cobine PA, Nishimura T et al. COX19 mediates the transduction of a mitochondrial redox signal from SCO1 that regulates ATP7A-mediated cellular copper efflux. Mol. Biol. Cell, 24(6), 683-691 (2013).

39. Kawamata $\mathrm{H}$, Manfredi G. Different regulation of wild-type and mutant $\mathrm{Cu}, \mathrm{Zn}$ superoxide dismutase localization in mammalian mitochondria. Hum. Mol. Genet., 17(21), 3303-3317 (2008).

* Determined that mitochondrial localisation of SOD1 is dependent upon oxygen concentration

40. Cobine PA, Ojeda LD, Rigby KM, Winge DR. Yeast contain a nonproteinaceous pool of copper in the mitochondrial matrix. J. Biol. Chem., 279(14), 14447-14455 (2004). 
41. Cobine PA, Pierrel F, Bestwick ML, Winge DR. Mitochondrial matrix copper complex used in metallation of cytochrome oxidase and superoxide dismutase. J. Biol. Chem., 281(48), 36552-36559 (2006).

42. Fukai T, Ushio-Fukai M. Superoxide dismutases: role in redox signaling, vascular function, and diseases. Antioxid. Redox Signal., 15(6), 1583-1606 (2011).

43. Sensi SL, Ton-That D, Sullivan PG et al. Modulation of mitochondrial function by endogenous Zn2+ pools. Proc. Natl. Acad. Sci. U. S. A., 100(10), 6157-6162 (2003).

44. Dittmer PJ, Miranda JG, Gorski JA, Palmer AE. Genetically encoded sensors to elucidate spatial distribution of cellular zinc. J. Biol. Chem., 284(24), 1628916297 (2009).

45. Miranda JG, Weaver AL, Qin Y et al. New alternately colored FRET sensors for simultaneous monitoring of $\mathrm{Zn}(2)(+)$ in multiple cellular locations. PLoS One, 7(11), e49371 (2012).

46. Park JG, Qin Y, Galati DF, Palmer AE. New sensors for quantitative measurement of mitochondrial $\mathrm{Zn}(2+)$. ACS Chem. Biol., 7(10), 1636-1640 (2012).

47. Eide DJ. Zinc transporters and the cellular trafficking of zinc. Biochim. Biophys. Acta, 1763(7), 711-722 (2006).

48. Burri L, Vascotto K, Fredersdorf S, Tiedt R, Hall MN, Lithgow T. Zim17, a novel zinc finger protein essential for protein import into mitochondria. J. Biol. Chem., 279(48), 50243-50249 (2004).

49. Minczuk M, Kolasinska-Zwierz P, Murphy MP, Papworth MA. Construction and testing of engineered zinc-finger proteins for sequence-specific modification of mtDNA. Nat. Protoc., 5(2), 342-356 (2010).

50. Gammage PA, Rorbach J, Vincent AI, Rebar EJ, Minczuk M. Mitochondrially targeted ZFNs for selective degradation of pathogenic mitochondrial genomes bearing large-scale deletions or point mutations. EMBO Mol. Med., 6(4), 458466 (2014).

51. Harding AE. Clinical features and classification of inherited ataxias. Adv. Neurol., 61, 1-14 (1993).

52. Parkinson MH, Boesch S, Nachbauer W, Mariotti C, Giunti P. Clinical features of Friedreich's ataxia: classical and atypical phenotypes. J. Neurochem., 126 Suppl 1, 103-117 (2013).

53. Koeppen AH. Friedreich's ataxia: pathology, pathogenesis, and molecular genetics. J. Neurol. Sci., 303(1-2), 1-12 (2011).

54. Koeppen AH, Ramirez RL, Becker AB, Feustel PJ, Mazurkiewicz JE. Friedreich Ataxia: Failure of GABA-ergic and Glycinergic Synaptic Transmission in the Dentate Nucleus. J. Neuropathol. Exp. Neurol., 74(2), 166176 (2015).

55. Cossee M, Puccio H, Gansmuller A et al. Inactivation of the Friedreich ataxia mouse gene leads to early embryonic lethality without iron accumulation. Hum. Mol. Genet., 9(8), 1219-1226 (2000).

56. Schmucker S, Martelli A, Colin F et al. Mammalian frataxin: an essential function for cellular viability through an interaction with a preformed ISCU/NFS1/ISD11 iron-sulfur assembly complex. PLoS One, 6(1), e16199 (2011).

* Demonstrated the role of frataxin in iron-sulfur cluster assembly 
57. Rotig A, de Lonlay P, Chretien D et al. Aconitase and mitochondrial ironsulphur protein deficiency in Friedreich ataxia. Nat. Genet., 17(2), 215-217 (1997).

58. Wilson RB, Roof DM. Respiratory deficiency due to loss of mitochondrial DNA in yeast lacking the frataxin homologue. Nat. Genet., 16(4), 352-357 (1997).

59. Anderson PR, Kirby K, Hilliker AJ, Phillips JP. RNAi-mediated suppression of the mitochondrial iron chaperone, frataxin, in Drosophila. Hum. Mol. Genet, 14(22), 3397-3405 (2005).

60. Long S, Jirku M, Mach J et al. Ancestral roles of eukaryotic frataxin: mitochondrial frataxin function and heterologous expression of hydrogenosomal Trichomonas homologues in trypanosomes. Mol. Microbiol., 69(1), 94-109 (2008).

61. Martelli A, Wattenhofer-Donze M, Schmucker S, Bouvet S, Reutenauer L, Puccio H. Frataxin is essential for extramitochondrial Fe-S cluster proteins in mammalian tissues. Hum. Mol. Genet., 16(22), 2651-2658 (2007).

62. Rouault TA. Biogenesis of iron-sulfur clusters in mammalian cells: new insights and relevance to human disease. Dis. Model. Mech., 5(2), 155-164 (2012).

63. Sharma AK, Pallesen LJ, Spang RJ, Walden WE. Cytosolic iron-sulfur cluster assembly (CIA) system: factors, mechanism, and relevance to cellular iron regulation. J. Biol. Chem., 285(35), 26745-26751 (2010).

64. Huang ML, Becker EM, Whitnall M, Suryo Rahmanto Y, Ponka P, Richardson DR. Elucidation of the mechanism of mitochondrial iron loading in Friedreich's ataxia by analysis of a mouse mutant. Proc. Natl. Acad. Sci. U. S. A., 106(38), 16381-16386 (2009).

65. Whitnall M, Suryo Rahmanto Y, Huang ML et al. Identification of nonferritin mitochondrial iron deposits in a mouse model of Friedreich ataxia. Proc. Natl. Acad. Sci. U. S. A., 109(50), 20590-20595 (2012).

66. Huang ML, Lane DJ, Richardson DR. Mitochondrial mayhem: the mitochondrion as a modulator of iron metabolism and its role in disease. Antioxid. Redox Signal., 15(12), 3003-3019 (2011).

67. Radisky DC, Babcock MC, Kaplan J. The yeast frataxin homologue mediates mitochondrial iron efflux. Evidence for a mitochondrial iron cycle. J. Biol. Chem., 274(8), 4497-4499 (1999).

68. Velasco-Sanchez D, Aracil A, Montero R et al. Combined therapy with idebenone and deferiprone in patients with Friedreich's ataxia. Cerebellum, 10(1), 1-8 (2011).

69. Boddaert N, Le Quan Sang KH, Rotig A et al. Selective iron chelation in Friedreich ataxia: biologic and clinical implications. Blood, 110(1), 401-408 (2007).

70. Waldvogel D, van Gelderen P, Hallett M. Increased iron in the dentate nucleus of patients with Friedrich's ataxia. Ann. Neurol., 46(1), 123-125 (1999).

71. Bonilha da Silva C, Bergo FP, D'Abreu A, Cendes F, Lopes-Cendes I, Franca $\mathrm{MC}$, Jr. Dentate nuclei T2 relaxometry is a reliable neuroimaging marker in Friedreich's ataxia. Eur. J. Neurol., 21(8), 1131-1136 (2014).

72. Synofzik M, Godau J, Lindig T, Schols L, Berg D. Transcranial sonography reveals cerebellar, nigral, and forebrain abnormalities in Friedreich's ataxia. Neurodegener. Dis., 8(6), 470-475 (2011). 
73. Solbach K, Kraff O, Minnerop M et al. Cerebellar pathology in Friedreich's ataxia: atrophied dentate nuclei with normal iron content. Neuroimage Clin., 6, 93-99 (2014).

74. Bradley JL, Blake JC, Chamberlain S, Thomas PK, Cooper JM, Schapira AH. Clinical, biochemical and molecular genetic correlations in Friedreich's ataxia. Hum. Mol. Genet., 9(2), 275-282 (2000).

75. Koeppen AH, Michael SC, Knutson MD et al. The dentate nucleus in Friedreich's ataxia: the role of iron-responsive proteins. Acta Neuropathol., 114(2), 163-173 (2007).

76. Koeppen AH, Ramirez RL, Yu D et al. Friedreich's ataxia causes redistribution of iron, copper, and zinc in the dentate nucleus. Cerebellum, 11(4), 845-860 (2012).

77. Koeppen AH, Kuntzsch EC, Bjork ST, Ramirez RL, Mazurkiewicz JE, Feustel PJ. Friedreich ataxia: metal dysmetabolism in dorsal root ganglia. Acta Neuropathol. Commun., 1(1), 26 (2013).

78. Bayot A, Santos R, Camadro JM, Rustin P. Friedreich's ataxia: the vicious circle hypothesis revisited. BMC Med., 9, 112 (2011).

79. Wong A, Yang J, Cavadini $\mathrm{P}$ et al. The Friedreich's ataxia mutation confers cellular sensitivity to oxidant stress which is rescued by chelators of iron and calcium and inhibitors of apoptosis. Hum. Mol. Genet., 8(3), 425-430 (1999).

80. Tan G, Chen LS, Lonnerdal B, Gellera C, Taroni FA, Cortopassi GA. Frataxin expression rescues mitochondrial dysfunctions in FRDA cells. Hum. Mol. Genet., 10(19), 2099-2107 (2001).

81. Calmels N, Schmucker S, Wattenhofer-Donze $\mathrm{M}$ et al. The first cellular models based on frataxin missense mutations that reproduce spontaneously the defects associated with Friedreich ataxia. PLoS One, 4(7), e6379 (2009).

82. Puccio H, Simon D, Cossee M et al. Mouse models for Friedreich ataxia exhibit cardiomyopathy, sensory nerve defect and Fe-S enzyme deficiency followed by intramitochondrial iron deposits. Nat. Genet., 27(2), 181-186 (2001).

83. Campanella A, Rovelli E, Santambrogio P, Cozzi A, Taroni F, Levi S. Mitochondrial ferritin limits oxidative damage regulating mitochondrial iron availability: hypothesis for a protective role in Friedreich ataxia. Hum. Mol. Genet., 18(1), 1-11 (2009).

84. Li K, Besse EK, Ha D, Kovtunovych G, Rouault TA. Iron-dependent regulation of frataxin expression: implications for treatment of Friedreich ataxia. Hum. Mol. Genet., 17(15), 2265-2273 (2008).

85. Sohn YS, Breuer W, Munnich A, Cabantchik ZI. Redistribution of accumulated cell iron: a modality of chelation with therapeutic implications. Blood, 111(3), 1690-1699 (2008).

86. Devos D, Moreau C, Devedjian JC et al. Targeting Chelatable Iron as a Therapeutic Modality in Parkinson's Disease. Antioxid. Redox Signal., 21(2), 195-210 (2014).

** First study to demonstrate clinical efficacy of iron chelation for Parkinson's disease

87. Soriano S, Llorens JV, Blanco-Sobero L et al. Deferiprone and idebenone rescue frataxin depletion phenotypes in a Drosophila model of Friedreich's ataxia. Gene, 521(2), 274-281 (2013).

88. Kakhlon O, Manning H, Breuer W et al. Cell functions impaired by frataxin deficiency are restored by drug-mediated iron relocation. Blood, 112(13), 52195227 (2008). 
89. Li L, Voullaire L, Sandi C et al. Pharmacological screening using an FXNEGFP cellular genomic reporter assay for the therapy of Friedreich ataxia. PloS One, 8(2), e55940 (2013).

90. Pandolfo M, Arpa J, Delatycki MB et al. Deferiprone in Friedreich ataxia: a 6month randomized controlled trial. Ann. Neurol., 76(4), 509-521 (2014).

91. Bradley WG. Overview of motor neuron disease: classification and nomenclature. Clin. Neurosci., 3(6), 323-326 (1995).

92. Al-Chalabi A, Jones A, Troakes C, King A, Al-Sarraj S, van den Berg LH. The genetics and neuropathology of amyotrophic lateral sclerosis. Acta Neuropathol., 124(3), 339-352 (2012).

93. Rosen DR, Siddique T, Patterson D et al. Mutations in $\mathrm{Cu} / \mathrm{Zn}$ superoxide dismutase gene are associated with familial amyotrophic lateral sclerosis. Nature, 362(6415), 59-62 (1993).

94. Leblond CS, Kaneb HM, Dion PA, Rouleau GA. Dissection of genetic factors associated with amyotrophic lateral sclerosis. Exp. Neurol., 262 Pt B, 91-101 (2014).

95. Marangi G, Traynor BJ. Genetic causes of amyotrophic lateral sclerosis: New genetic analysis methodologies entailing new opportunities and challenges. Brain Res., 1607, 75-93 (2015).

96. Sasaki S, Iwata M. Mitochondrial alterations in the spinal cord of patients with sporadic amyotrophic lateral sclerosis. J. Neuropathol. Exp. Neurol., 66(1), 1016 (2007).

97. Kawamata H, Manfredi G. Mitochondrial dysfunction and intracellular calcium dysregulation in ALS. Mech. Ageing Dev., 131(7-8), 517-526 (2010).

98. Carri MT, Valle C, Bozzo F, Cozzolino M. Oxidative stress and mitochondrial damage: importance in non-SOD1 ALS. Front. Cell Neurosci., 9, 41 (2015).

99. Bannwarth S, Ait-El-Mkadem S, Chaussenot A et al. A mitochondrial origin for frontotemporal dementia and amyotrophic lateral sclerosis through CHCHD10 involvement. Brain, 137(Pt 8), 2329-2345 (2014).

100. Bartolome F, Wu HC, Burchell VS et al. Pathogenic VCP mutations induce mitochondrial uncoupling and reduced ATP levels. Neuron, 78(1), 57-64 (2013).

101. Yin HZ, Nalbandian A, Hsu CI et al. Slow development of ALS-like spinal cord pathology in mutant valosin-containing protein gene knock-in mice. Cell Death Dis., 3, e374 (2012).

102. Magrane J, Cortez C, Gan WB, Manfredi G. Abnormal mitochondrial transport and morphology are common pathological denominators in SOD1 and TDP43 ALS mouse models. Hum. Mol. Genet., (2013).

103. Wang W, Li L, Lin WL et al. The ALS disease-associated mutant TDP-43 impairs mitochondrial dynamics and function in motor neurons. Hum. Mol. Genet., 22(23), 4706-4719 (2013).

104. Huang C, Tong J, Bi F et al. Entorhinal cortical neurons are the primary targets of FUS mislocalization and ubiquitin aggregation in FUS transgenic rats. Hum. Mol. Genet., 21(21), 4602-4614 (2012).

105. Luo G, Yi J, Ma C et al. Defective mitochondrial dynamics is an early event in skeletal muscle of an amyotrophic lateral sclerosis mouse model. PLoS One, 8(12), e82112 (2013).

106. Vande Velde C, McDonald KK, Boukhedimi Y et al. Misfolded SOD1 associated with motor neuron mitochondria alters mitochondrial shape and distribution prior to clinical onset. PLoS One, 6(7), e22031 (2011). 
107. Vinsant S, Mansfield C, Jimenez-Moreno R et al. Characterization of early pathogenesis in the SOD1(G93A) mouse model of ALS: part II, results and discussion. Brain Behav., 3(4), 431-457 (2013).

108. Veyrat-Durebex C, Corcia P, Mucha A et al. Iron metabolism disturbance in a French cohort of ALS patients. Biomed. Res. Int., 2014, 485723 (2014).

109. Yu J, Qi F, Wang N et al. Increased iron level in motor cortex of amyotrophic lateral sclerosis patients: an in vivo MR study. Amyotroph. Lateral Scler. Frontotemporal Degener., 15(5-6), 357-361 (2014).

110. Adachi Y, Sato N, Saito Y et al. Usefulness of SWI for the Detection of Iron in the Motor Cortex in Amyotrophic Lateral Sclerosis. J. Neuroimaging, (2014).

111. Ignjatovic A, Stevic Z, Lavrnic S, Dakovic M, Bacic G. Brain iron MRI: a biomarker for amyotrophic lateral sclerosis. J. Magn. Reson. Imaging, 38(6), 1472-1479 (2013).

112. Jeong SY, Rathore KI, Schulz K, Ponka P, Arosio P, David S. Dysregulation of iron homeostasis in the CNS contributes to disease progression in a mouse model of amyotrophic lateral sclerosis. J. Neurosci., 29(3), 610-619 (2009).

113. Dang TN, Lim NK, Grubman A et al. Increased metal content in the TDP43(A315T) transgenic mouse model of frontotemporal lobar degeneration and amyotrophic lateral sclerosis. Front. Aging Neurosci., 6, 15 (2014).

114. Furukawa Y. Pathological roles of wild-type cu, zn-superoxide dismutase in amyotrophic lateral sclerosis. Neurol. Res. Int., 2012, 323261 (2012).

115. Vande Velde C, Miller TM, Cashman NR, Cleveland DW. Selective association of misfolded ALS-linked mutant SOD1 with the cytoplasmic face of mitochondria. Proc. Natl. Acad. Sci. U. S. A., 105(10), 4022-4027 (2008).

116. Israelson A, Arbel N, Da Cruz S et al. Misfolded mutant SOD1 directly inhibits VDAC1 conductance in a mouse model of inherited ALS. Neuron, 67(4), 575587 (2010).

117. Li Q, Vande Velde C, Israelson A et al. ALS-linked mutant superoxide dismutase 1 (SOD1) alters mitochondrial protein composition and decreases protein import. Proc. Natl. Acad. Sci. U. S. A., 107(49), 21146-21151 (2010).

118. Pedrini S, Sau D, Guareschi S et al. ALS-linked mutant SOD1 damages mitochondria by promoting conformational changes in Bcl-2. Hum. Mol. Genet., 19(15), 2974-2986 (2010).

119. Fischer LR, Igoudjil A, Magrane J et al. SOD1 targeted to the mitochondrial intermembrane space prevents motor neuropathy in the Sod1 knockout mouse. Brain, 134(Pt 1), 196-209 (2011).

120. Mattiazzi M, D'Aurelio M, Gajewski CD et al. Mutated human SOD1 causes dysfunction of oxidative phosphorylation in mitochondria of transgenic mice. J. Biol. Chem., 277(33), 29626-29633 (2002).

121. Jaarsma D, Rognoni F, van Duijn W, Verspaget HW, Haasdijk ED, Holstege JC. $\mathrm{CuZn}$ superoxide dismutase (SOD1) accumulates in vacuolated mitochondria in transgenic mice expressing amyotrophic lateral sclerosis-linked SOD1 mutations. Acta Neuropathol., 102(4), 293-305 (2001).

122. Igoudjil A, Magrane J, Fischer LR et al. In vivo pathogenic role of mutant SOD1 localized in the mitochondrial intermembrane space. J. Neurosci., 31(44), 15826-15837 (2011).

123. Parone PA, Da Cruz S, Han JS et al. Enhancing mitochondrial calcium buffering capacity reduces aggregation of misfolded SOD1 and motor neuron cell death without extending survival in mouse models of inherited amyotrophic lateral sclerosis. J. Neurosci., 33(11), 4657-4671 (2013). 
124. Sturtz LA, Diekert K, Jensen LT, Lill R, Culotta VC. A fraction of yeast Cu,Znsuperoxide dismutase and its metallochaperone, CCS, localize to the intermembrane space of mitochondria. A physiological role for SOD1 in guarding against mitochondrial oxidative damage. J. Biol. Chem., 276(41), 38084-38089 (2001).

125. Field LS, Furukawa Y, O'Halloran TV, Culotta VC. Factors controlling the uptake of yeast copper/zinc superoxide dismutase into mitochondria. J. Biol. Chem., 278(30), 28052-28059 (2003).

126. Kawamata H, Manfredi G. Import, maturation, and function of SOD1 and its copper chaperone CCS in the mitochondrial intermembrane space. Antioxid. Redox Signal., 13(9), 1375-1384 (2010).

127. Lang L, Kurnik M, Danielsson J, Oliveberg M. Fibrillation precursor of superoxide dismutase 1 revealed by gradual tuning of the protein-folding equilibrium. Proc. Natl. Acad. Sci. U. S. A., 109(44), 17868-17873 (2012).

* Demonstrated that SOD1 aggregation is driven by the unfolded immature monomer

128. Prudencio M, Hart PJ, Borchelt DR, Andersen PM. Variation in aggregation propensities among ALS-associated variants of SOD1: correlation to human disease. Hum. Mol. Genet., 18(17), 3217-3226 (2009).

129. Acevedo-Arozena A, Kalmar B, Essa S et al. A comprehensive assessment of the SOD1G93A low-copy transgenic mouse, which models human amyotrophic lateral sclerosis. Dis. Model. Mech., 4(5), 686-700 (2011).

130. Deitch JS, Alexander GM, Bensinger A, Yang S, Jiang JT, Heiman-Patterson TD. Phenotype of transgenic mice carrying a very low copy number of the mutant human G93A superoxide dismutase-1 gene associated with amyotrophic lateral sclerosis. PloS One, 9(6), e99879 (2014).

131. Jaarsma D, Haasdijk ED, Grashorn JA et al. Human $\mathrm{Cu} / \mathrm{Zn}$ superoxide dismutase (SOD1) overexpression in mice causes mitochondrial vacuolization, axonal degeneration, and premature motoneuron death and accelerates motoneuron disease in mice expressing a familial amyotrophic lateral sclerosis mutant SOD1. Neurobiol. Dis., 7(6 Pt B), 623-643 (2000).

132. Graffmo KS, Forsberg K, Bergh $\mathrm{J}$ et al. Expression of wild-type human superoxide dismutase-1 in mice causes amyotrophic lateral sclerosis. Hum. Mol. Genet., 22(1), 51-60 (2013).

133. Jonsson PA, Graffmo KS, Andersen PM et al. Disulphide-reduced superoxide dismutase-1 in CNS of transgenic amyotrophic lateral sclerosis models. Brain, 129(Pt 2), 451-464 (2006).

134. Son M, Leary SC, Romain N et al. Isolated cytochrome c oxidase deficiency in G93A SOD1 mice overexpressing CCS protein. J. Biol. Chem., 283(18), 1226712275 (2008).

135. Son M, Puttaparthi K, Kawamata $\mathrm{H}$ et al. Overexpression of CCS in G93ASOD1 mice leads to accelerated neurological deficits with severe mitochondrial pathology. Proc. Natl. Acad. Sci. U. S. A., 104(14), 6072-6077 (2007).

136. Bahadorani S, Mukai ST, Rabie J, Beckman JS, Phillips JP, Hilliker AJ. Expression of zinc-deficient human superoxide dismutase in Drosophila neurons produces a locomotor defect linked to mitochondrial dysfunction. Neurobiol. Aging, 34(10), 2322-2330 (2013).

137. Hadzhieva M, Kirches E, Wilisch-Neumann A et al. Dysregulation of iron protein expression in the G93A model of amyotrophic lateral sclerosis. Neuroscience, 230, 94-101 (2013). 
138. Wang Q, Zhang X, Chen S et al. Prevention of motor neuron degeneration by novel iron chelators in SOD1(G93A) transgenic mice of amyotrophic lateral sclerosis. Neurodegener. Dis., 8(5), 310-321 (2011).

139. Soon CP, Donnelly PS, Turner BJ et al. Diacetylbis(N(4)methylthiosemicarbazonato) copper(II) (CuII(atsm)) protects against peroxynitrite-induced nitrosative damage and prolongs survival in amyotrophic lateral sclerosis mouse model. J. Biol. Chem., 286(51), 44035-44044 (2011).

140. McAllum EJ, Lim NK, Hickey JL et al. Therapeutic effects of Cu(II)(atsm) in the SOD1-G37R mouse model of amyotrophic lateral sclerosis. Amyotroph. Lateral Scler. Frontotemporal Degener., 14(7-8), 586-590 (2013).

141. Roberts BR, Lim NK, McAllum EJ et al. Oral Treatment with CuII(atsm) Increases Mutant SOD1 In Vivo but Protects Motor Neurons and Improves the Phenotype of a Transgenic Mouse Model of Amyotrophic Lateral Sclerosis. J. Neurosci., 34(23), 8021-8031 (2014).

* $\mathrm{Cu}^{\mathrm{II}}(\mathrm{atsm})$ delays the onset of amyotrophic lateral sclerosis symptoms in mice via delivery of copper to SOD1

142. Beckman J, Williams J, Beilby P et al. Cu-ATSM: An effective treatment for high-expressing G93A-SOD1 mice expressing the human copper chaperone for SOD1 (CCS). Amyotroph. Lateral Scler. Frontotemporal Degener., 15(S1), 45 (2014).

143. Kupershmidt L, Weinreb O, Amit T, Mandel S, Carri MT, Youdim MB. Neuroprotective and neuritogenic activities of novel multimodal iron-chelating drugs in motor-neuron-like NSC-34 cells and transgenic mouse model of amyotrophic lateral sclerosis. FASEB J., 23(11), 3766-3779 (2009).

144. Zheng H, Weiner LM, Bar-Am O et al. Design, synthesis, and evaluation of novel bifunctional iron-chelators as potential agents for neuroprotection in Alzheimer's, Parkinson's, and other neurodegenerative diseases. Bioorg. Med. Chem., 13(3), 773-783 (2005).

145. Levine T, Hank N, Saperstein D, Bradley W, Cox P. Zinc inhibition of BMAA toxicity. Amyotroph. Lateral Scler., 12(Suppl. 1), 165 (2011).

146. Riemer J, Kins S. Axonal transport and mitochondrial dysfunction in Alzheimer's disease. Neurodegener. Dis., 12(3), 111-124 (2013).

147. Aliev G, Seyidova D, Neal ML et al. Atherosclerotic lesions and mitochondria DNA deletions in brain microvessels as a central target for the development of human $\mathrm{AD}$ and $\mathrm{AD}-$ like pathology in aged transgenic mice. Ann. N. Y. Acad. Sci., 977, 45-64 (2002).

148. Hirai K, Aliev G, Nunomura A et al. Mitochondrial abnormalities in Alzheimer's disease. J. Neurosci., 21(9), 3017-3023 (2001).

149. Kish SJ, Bergeron C, Rajput A et al. Brain cytochrome oxidase in Alzheimer's disease. J. Neurochem., 59(2), 776-779 (1992).

150. Mutisya EM, Bowling AC, Beal MF. Cortical cytochrome oxidase activity is reduced in Alzheimer's disease. J. Neurochem., 63(6), 2179-2184 (1994).

151. Maurer I, Zierz S, Moller HJ. A selective defect of cytochrome c oxidase is present in brain of Alzheimer disease patients. Neurobiol. Aging, 21(3), 455462 (2000).

152. Phillips NR, Simpkins JW, Roby RK. Mitochondrial DNA deletions in Alzheimer's brains: a review. Alzheimers Dement., 10(3), 393-400 (2014).

153. Hauptmann S, Scherping I, Drose S et al. Mitochondrial dysfunction: an early event in Alzheimer pathology accumulates with age in AD transgenic mice. Neurobiol. Aging, 30(10), 1574-1586 (2009). 
154. Fu YJ, Xiong S, Lovell MA, Lynn BC. Quantitative proteomic analysis of mitochondria in aging PS-1 transgenic mice. Cell Mol. Neurobiol., 29(5), 649664 (2009).

155. Moreira PI, Carvalho C, Zhu X, Smith MA, Perry G. Mitochondrial dysfunction is a trigger of Alzheimer's disease pathophysiology. Biochim. Biophys. Acta, 1802(1), 2-10 (2010).

156. Lee SH, Kim KR, Ryu SY et al. Impaired short-term plasticity in mossy fiber synapses caused by mitochondrial dysfunction of dentate granule cells is the earliest synaptic deficit in a mouse model of Alzheimer's disease. J. Neurosci., 32(17), 5953-5963 (2012).

157. Manczak M, Anekonda TS, Henson E, Park BS, Quinn J, Reddy PH. Mitochondria are a direct site of A beta accumulation in Alzheimer's disease neurons: implications for free radical generation and oxidative damage in disease progression. Hum. Mol. Genet., 15(9), 1437-1449 (2006).

158. Lustbader JW, Cirilli M, Lin C et al. ABAD directly links Abeta to mitochondrial toxicity in Alzheimer's disease. Science, 304(5669), 448-452 (2004).

159. Crouch PJ, Blake R, Duce JA et al. Copper-dependent inhibition of human cytochrome c oxidase by a dimeric conformer of amyloid-beta1-42. J. Neurosci., 25(3), 672-679 (2005).

160. Ayton S, Lei P, Bush AI. Biometals and Their Therapeutic Implications in Alzheimer's Disease. Neurotherapeutics, (2014).

161. Bartzokis G, Sultzer D, Mintz J et al. In vivo evaluation of brain iron in Alzheimer's disease and normal subjects using MRI. Biol. Psychiatry, 35(7), 480-487 (1994).

162. Honda K, Smith MA, Zhu X et al. Ribosomal RNA in Alzheimer disease is oxidized by bound redox-active iron. J. Biol. Chem., 280(22), 20978-20986 (2005).

163. Smith MA, Harris PL, Sayre LM, Perry G. Iron accumulation in Alzheimer disease is a source of redox-generated free radicals. Proc. Natl. Acad. Sci. U. S. A., 94(18), 9866-9868 (1997).

164. Schrag M, Mueller C, Oyoyo U, Smith MA, Kirsch WM. Iron, zinc and copper in the Alzheimer's disease brain: a quantitative meta-analysis. Some insight on the influence of citation bias on scientific opinion. Prog. Neurobiol., 94(3), 296306 (2011).

165. Rembach A, Hare DJ, Lind M et al. Decreased copper in Alzheimer's disease brain is predominantly in the soluble extractable fraction. Int. J. Alzheimers Dis., 2013, 623241 (2013).

166. Miller LM, Wang Q, Telivala TP, Smith RJ, Lanzirotti A, Miklossy J. Synchrotron-based infrared and X-ray imaging shows focalized accumulation of $\mathrm{Cu}$ and $\mathrm{Zn}$ co-localized with beta-amyloid deposits in Alzheimer's disease. J. Struct. Biol., 155(1), 30-37 (2006).

167. Ayton S, Lei P, Duce JA et al. Ceruloplasmin dysfunction and therapeutic potential for Parkinson disease. Ann. Neurol., 73(4), 554-559 (2013).

168. Wong BX, Tsatsanis A, Lim LQ, Adlard PA, Bush AI, Duce JA. beta-Amyloid Precursor Protein Does Not Possess Ferroxidase Activity but Does Stabilize the Cell Surface Ferrous Iron Exporter Ferroportin. PLoS One, 9(12), e114174 (2014). 
169. Duce JA, Tsatsanis A, Cater MA et al. Iron-export ferroxidase activity of betaamyloid precursor protein is inhibited by zinc in Alzheimer's disease. Cell, 142(6), 857-867 (2010).

170. Lei $\mathrm{P}$, Ayton S, Finkelstein DI et al. Tau deficiency induces parkinsonism with dementia by impairing APP-mediated iron export. Nat. Med., 18(2), 291-295 (2012).

171. Wu WS, Zhao YS, Shi ZH et al. Mitochondrial ferritin attenuates beta-amyloidinduced neurotoxicity: reduction in oxidative damage through the Erk/P38 mitogen-activated protein kinase pathways. Antioxid. Redox Signal., 18(2), 158169 (2013).

172. Adlard PA, Cherny RA, Finkelstein DI et al. Rapid restoration of cognition in Alzheimer's transgenic mice with 8-hydroxy quinoline analogs is associated with decreased interstitial Abeta. Neuron, 59(1), 43-55 (2008).

173. Cherny RA, Atwood CS, Xilinas ME et al. Treatment with a copper-zinc chelator markedly and rapidly inhibits beta-amyloid accumulation in Alzheimer's disease transgenic mice. Neuron, 30(3), 665-676 (2001).

174. White AR, Du T, Laughton KM et al. Degradation of the Alzheimer disease amyloid beta-peptide by metal-dependent up-regulation of metalloprotease activity. J. Biol. Chem., 281(26), 17670-17680 (2006).

* Discovered metal ionophore mechanism of action for clioquinol

175. Crouch PJ, Savva MS, Hung LW et al. The Alzheimer's therapeutic PBT2 promotes amyloid-beta degradation and GSK3 phosphorylation via a metal chaperone activity. J. Neurochem., 119(1), 220-230 (2011).

176. Lei P, Ayton S, Appukuttan AT et al. Clioquinol rescues Parkinsonism and dementia phenotypes of the tau knockout mouse. Neurobiol. Dis., In Press (2015).

177. Malm TM, Iivonen $\mathrm{H}$, Goldsteins $\mathrm{G}$ et al. Pyrrolidine dithiocarbamate activates Akt and improves spatial learning in APP/PS1 mice without affecting betaamyloid burden. J. Neurosci., 27(14), 3712-3721 (2007).

178. Kupershmidt L, Amit T, Bar-Am O, Youdim MB, Weinreb O. The novel multitarget iron chelating-radical scavenging compound M30 possesses beneficial effects on major hallmarks of Alzheimer's disease. Antioxid. Redox Signal., 17(6), 860-877 (2012).

179. Kamalinia G, Khodagholi F, Atyabi F et al. Enhanced brain delivery of deferasirox-lactoferrin conjugates for iron chelation therapy in neurodegenerative disorders: in vitro and in vivo studies. Mol. Pharm., 10(12), 4418-4431 (2013).

180. Crouch PJ, Hung LW, Adlard PA et al. Increasing $\mathrm{Cu}$ bioavailability inhibits Abeta oligomers and tau phosphorylation. Proc. Natl. Acad. Sci. U. S. A., 106(2), 381-386 (2009).

181. Crapper McLachlan DR, Dalton AJ, Kruck TP et al. Intramuscular desferrioxamine in patients with Alzheimer's disease. Lancet, 337(8753), 13041308 (1991).

182. Ritchie CW, Bush AI, Mackinnon A et al. Metal-protein attenuation with iodochlorhydroxyquin (clioquinol) targeting Abeta amyloid deposition and toxicity in Alzheimer disease: a pilot phase 2 clinical trial. Arch. Neurol., 60(12), 1685-1691 (2003).

183. Lannfelt L, Blennow K, Zetterberg H et al. Safety, efficacy, and biomarker findings of PBT2 in targeting Abeta as a modifying therapy for Alzheimer's 
disease: a phase IIa, double-blind, randomised, placebo-controlled trial. Lancet Neurol., 7(9), 779-786 (2008).

184. Faux NG, Ritchie CW, Gunn A et al. PBT2 rapidly improves cognition in Alzheimer's Disease: additional phase II analyses. J. Alzheimers Dis., 20(2), 509-516 (2010).

185. Bano D, Zanetti F, Mende Y, Nicotera P. Neurodegenerative processes in Huntington's disease. Cell Death Dis., 2, e228 (2011).

186. Duan W, Jiang M, Jin J. Metabolism in HD: still a relevant mechanism? Mov. Disord., 29(11), 1366-1374 (2014).

187. Muller M, Leavitt BR. Iron dysregulation in Huntington's disease. $J$. Neurochem., 130(3), 328-350 (2014).

188. Dexter DT, Carayon A, Javoy-Agid F et al. Alterations in the levels of iron, ferritin and other trace metals in Parkinson's disease and other neurodegenerative diseases affecting the basal ganglia. Brain, 114 ( Pt 4), 19531975 (1991).

189. Loeffler DA, LeWitt PA, Juneau PL et al. Increased regional brain concentrations of ceruloplasmin in neurodegenerative disorders. Brain Res., 738(2), 265-274 (1996).

190. Rosas HD, Chen YI, Doros G et al. Alterations in brain transition metals in Huntington disease: an evolving and intricate story. Arch. Neurol., 69(7), 887893 (2012).

191. Fox JH, Kama JA, Lieberman G et al. Mechanisms of copper ion mediated Huntington's disease progression. PLoS One, 2(3), e334 (2007).

192. Chen J, Marks E, Lai B et al. Iron accumulates in Huntington's disease neurons: protection by deferoxamine. PLoS one, 8(10), e77023 (2013).

193. Perez P, Flores A, Santamaria A, Rios C, Galvan-Arzate S. Changes in transition metal contents in rat brain regions after in vivo quinolinate intrastriatal administration. Arch. Med. Res., 27(4), 449-452 (1996).

194. Martinez-Lazcano JC, Montes S, Sanchez-Mendoza MA et al. Sub-chronic copper pretreatment reduces oxidative damage in an experimental Huntington's disease model. Biol. Trace Elem. Res., 162(1-3), 211-218 (2014).

195. Hodges A, Strand AD, Aragaki AK et al. Regional and cellular gene expression changes in human Huntington's disease brain. Hum. Mol. Genet., 15(6), 965977 (2006).

196. Hilditch-Maguire P, Trettel F, Passani LA, Auerbach A, Persichetti F, MacDonald ME. Huntingtin: an iron-regulated protein essential for normal nuclear and perinuclear organelles. Hum. Mol. Genet., 9(19), 2789-2797 (2000).

197. Sheline CT, Zhu J, Zhang W, Shi C, Cai AL. Mitochondrial inhibitor models of Huntington's disease and Parkinson's disease induce zinc accumulation and are attenuated by inhibition of zinc neurotoxicity in vitro or in vivo. Neurodegener. Dis., 11(1), 49-58 (2013).

198. Cherny RA, Ayton S, Finkelstein DI, Bush AI, McColl G, Massa SM. PBT2 Reduces Toxicity in a C. elegans Model of polyQ Aggregation and Extends Lifespan, Reduces Striatal Atrophy and Improves Motor Performance in the R6/2 Mouse Model of Huntington's Disease. J. Huntingtons Dis., 1(2), 211-219 (2012).

199. Investigators HSGRH. Safety, tolerability, and efficacy of PBT2 in Huntington's disease: a phase 2, randomised, double-blind, placebo-controlled trial. Lancet Neurol., 14(1), 39-47 (2015). 
200. Litvan I, Chesselet M-F, Gasser T et al. The etiopathogenesis of Parkinson disease and suggestions for future research. Part II. J. Neuropathol. Exp. Neurol., 66(5), 329-336 (2007).

201. Spillantini MG, Schmidt ML, Lee VM, Trojanowski JQ, Jakes R, Goedert M. Alpha-synuclein in Lewy bodies. Nature, 388(6645), 839-840 (1997).

202. Goedert M. Alpha-synuclein and neurodegenerative diseases. Nat. Rev. Neurosci., 2(7), 492-501 (2001).

203. Schapira AH, Cooper JM, Dexter D, Jenner P, Clark JB, Marsden CD. Mitochondrial complex I deficiency in Parkinson's disease. Lancet, 1(8649), 1269 (1989).

204. Mizuno Y, Ohta S, Tanaka M et al. Deficiencies in complex I subunits of the respiratory chain in Parkinson's disease. Biochem. Biophys. Res. Commun., 163(3), 1450-1455 (1989).

205. Tanner CM, Kamel F, Ross GW et al. Rotenone, paraquat, and Parkinson's disease. Environ. Health Perspect., 119(6), 866-872 (2011).

206. Ayton S, Lei P. Nigral iron elevation is an invariable feature of Parkinson's disease and is a sufficient cause of neurodegeneration. Biomed. Res. Int., 2014, 581256 (2014).

207. Popescu BF, George MJ, Bergmann U et al. Mapping metals in Parkinson's and normal brain using rapid-scanning x-ray fluorescence. Phys. Med. Biol., 54(3), 651-663 (2009).

208. Davies KM, Bohic S, Carmona A et al. Copper pathology in vulnerable brain regions in Parkinson's disease. Neurobiol. Aging, 35(4), 858-866 (2014).

209. Mochizuki H, Imai H, Endo $\mathrm{K}$ et al. Iron accumulation in the substantia nigra of 1-methyl-4-phenyl-1,2,3,6-tetrahydropyridine (MPTP)-induced hemiparkinsonian monkeys. Neurosci. Lett., 168(1-2), 251-253 (1994).

210. Temlett JA, Landsberg JP, Watt F, Grime GW. Increased iron in the substantia nigra compacta of the MPTP-lesioned hemiparkinsonian African green monkey: evidence from proton microprobe elemental microanalysis. $J$. Neurochem., 62(1), 134-146 (1994).

211. Fleming RE, Migas MC, Holden CC et al. Transferrin receptor 2: continued expression in mouse liver in the face of iron overload and in hereditary hemochromatosis. Proc. Natl. Acad. Sci. U. S. A., 97(5), 2214-2219 (2000).

212. Lee DW, Rajagopalan S, Siddiq A et al. Inhibition of prolyl hydroxylase protects against 1-methyl-4-phenyl-1,2,3,6-tetrahydropyridine-induced neurotoxicity: model for the potential involvement of the hypoxia-inducible factor pathway in Parkinson disease. J. Biol. Chem., 284(42), 29065-29076 (2009).

213. Mastroberardino PG, Hoffman EK, Horowitz MP et al. A novel transferrin/TfR2-mediated mitochondrial iron transport system is disrupted in Parkinson's disease. Neurobiol. Dis., 34(3), 417-431 (2009).

214. Oestreicher E, Sengstock GJ, Riederer P, Olanow CW, Dunn AJ, Arendash GW. Degeneration of nigrostriatal dopaminergic neurons increases iron within the substantia nigra: a histochemical and neurochemical study. Brain Res., 660(1), 8-18 (1994).

215. Rios C, Alvarez-Vega R, Rojas P. Depletion of copper and manganese in brain after MPTP treatment of mice. Pharmacol. Toxicol., 76(6), 348-352 (1995).

216. Schipper HM, Vininsky R, Brull R, Small L, Brawer JR. Astrocyte mitochondria: a substrate for iron deposition in the aging rat substantia nigra. Exp. Neurol., 152(2), 188-196 (1998). 
217. Sian J, Dexter DT, Lees AJ et al. Alterations in glutathione levels in Parkinson's disease and other neurodegenerative disorders affecting basal ganglia. Ann. Neurol., 36(3), 348-355 (1994).

218. Pearce RK, Owen A, Daniel S, Jenner P, Marsden CD. Alterations in the distribution of glutathione in the substantia nigra in Parkinson's disease. $J$. Neural Transm., 104(6-7), 661-677 (1997).

219. Martin HL, Teismann P. Glutathione--a review on its role and significance in Parkinson's disease. FASEB J., 23(10), 3263-3272 (2009).

220. Lee DW, Kaur D, Chinta SJ, Rajagopalan S, Andersen JK. A disruption in ironsulfur center biogenesis via inhibition of mitochondrial dithiol glutaredoxin 2 may contribute to mitochondrial and cellular iron dysregulation in mammalian glutathione-depleted dopaminergic cells: implications for Parkinson's disease. Antioxid. Redox Signal., 11(9), 2083-2094 (2009).

221. Park JS, Koentjoro B, Veivers D, Mackay-Sim A, Sue CM. Parkinson's diseaseassociated human ATP13A2 (PARK9) deficiency causes zinc dyshomeostasis and mitochondrial dysfunction. Hum. Mol. Genet., 23(11), 2802-2815 (2014).

222. Kaur D, Yantiri F, Rajagopalan S et al. Genetic or pharmacological iron chelation prevents MPTP-induced neurotoxicity in vivo: a novel therapy for Parkinson's disease. Neuron, 37(6), 899-909 (2003).

223. Shi ZH, Nie G, Duan XL et al. Neuroprotective mechanism of mitochondrial ferritin on 6-hydroxydopamine-induced dopaminergic cell damage: implication for neuroprotection in Parkinson's disease. Antioxid. Redox Signal., 13(6), 783796 (2010).

224. Santiago M, Matarredona ER, Granero L, Cano J, Machado A. Neuroprotective effect of the iron chelator desferrioxamine against MPP+ toxicity on striatal dopaminergic terminals. J. Neurochem., 68(2), $732-738$ (1997).

225. Ben-Shachar D, Eshel G, Finberg JP, Youdim MB. The iron chelator desferrioxamine (Desferal) retards 6-hydroxydopamine-induced degeneration of nigrostriatal dopamine neurons. J. Neurochem., 56(4), 1441-1444 (1991).

226. Ben-Shachar D, Eshel G, Riederer P, Youdim MB. Role of iron and iron chelation in dopaminergic-induced neurodegeneration: implication for Parkinson's disease. Ann. Neurol., 32 Suppl, S105-110 (1992).

227. Lan J, Jiang DH. Desferrioxamine and vitamin E protect against iron and MPTP-induced neurodegeneration in mice. J. Neural Transm., 104(4-5), 469481 (1997).

228. Zhang Z, Zhang K, Du X, Li Y. Neuroprotection of desferrioxamine in lipopolysaccharide-induced nigrostriatal dopamine neuron degeneration. Mol. Med. Report., 5(2), 562-566 (2012).

229. Dexter DT, Statton SA, Whitmore C et al. Clinically available iron chelators induce neuroprotection in the 6-OHDA model of Parkinson's disease after peripheral administration. J. Neural Transm., 118(2), 223-231 (2011).

230. Liddell JR, Obando D, Liu J et al. Lipophilic adamantyl- or deferasirox-based conjugates of desferrioxamine $\mathrm{B}$ have enhanced neuroprotective capacity: implications for Parkinson disease. Free. Radic. Biol. Med., 60, 147-156 (2013).

231. Alcaraz-Zubeldia M, Rojas P, Boll C, Rios C. Neuroprotective effect of acute and chronic administration of copper (II) sulfate against MPP+ neurotoxicity in mice. Neurochem. Res., 26(1), 59-64 (2001).

232. Youdim MB, Grunblatt E, Mandel S. The copper chelator, D-penicillamine, does not attenuate MPTP induced dopamine depletion in mice. J. Neural Transm., 114(2), 205-209 (2007). 
233. Hung LW, Villemagne VL, Cheng L et al. The hypoxia imaging agent $\mathrm{CuII}(\mathrm{atsm})$ is neuroprotective and improves motor and cognitive functions in multiple animal models of Parkinson's disease. J. Exp. Med., 209(4), 837-854 (2012).

234. Shachar DB, Kahana N, Kampel V, Warshawsky A, Youdim MB. Neuroprotection by a novel brain permeable iron chelator, VK-28, against 6hydroxydopamine lession in rats. Neuropharmacology, 46(2), 254-263 (2004).

235. Gal S, Zheng $\mathrm{H}$, Fridkin $\mathrm{M}$, Youdim MBH. Novel multifunctional neuroprotective iron chelator-monoamine oxidase inhibitor drugs for neurodegenerative diseases. In vivo selective brain monoamine oxidase inhibition and prevention of MPTP-induced striatal dopamine depletion. $J$. Neurochem., 95(1), 79-88 (2005).

236. Gal S, Zheng H, Fridkin M, Youdim MB. Restoration of nigrostriatal dopamine neurons in post-MPTP treatment by the novel multifunctional brain-permeable iron chelator-monoamine oxidase inhibitor drug, M30. Neurotox. Res., 17(1), 15-27 (2010).

237. Mechlovich D, Amit T, Bar-Am O, Mandel S, Youdim MB, Weinreb O. The Novel Multi-Target Iron Chelator, M30 Modulates HIF-1alpha-Related Glycolytic Genes and Insulin Signaling Pathway in the Frontal Cortex of APP/PS1 Alzheimer's Disease Mice. Curr. Alzheimer Res., 11(2), 119-127 (2014). 